NBER WORKING PAPER SERIES

\title{
RURAL WINDFALL OR A NEW RESOURCE CURSE? COCA, INCOME, AND CIVIL CONFLICT IN COLOMBIA
}

\author{
Joshua D. Angrist \\ Adriana D. Kugler \\ Working Paper 11219 \\ http://www.nber.org/papers/w11219 \\ NATIONAL BUREAU OF ECONOMIC RESEARCH \\ 1050 Massachusetts Avenue \\ Cambridge, MA 02138 \\ March 2005
}

Special thanks go to Hector Mejia, Ines Parra, and Carlos Troncoso at DANE in Bogota, and to Patricia Cortes, Francisco Gallego, Jennifer Lao, Veronica Paz and Chris Smith for outstanding research assistance, and to David Autor, Alberto Abadie, Eli Berman, Robin Burgess, David Card, Joe Hotz, Ed Lazear, Daniel Mejia, Yona Rubinstein and seminar participants at Hebrew University, the NBER, Rochester, SOLE, Stanford GSB, Tel Aviv University, UCLA, UC-Berkeley, and UT Austin for helpful discussions and comments. The views expressed herein are those of the author(s) and do not necessarily reflect the views of the National Bureau of Economic Research.

(C) 2005 by Joshua D. Angrist and Adriana D. Kugler. All rights reserved. Short sections of text, not to exceed two paragraphs, may be quoted without explicit permission provided that full credit, including (C) notice, is given to the source. 
Rural Windfall or a New Resource Curse? Coca, Income, and Civil Conflict in Colombia Joshua D. Angrist and Adriana D. Kugler

NBER Working Paper No. 11219

March 2005

JEL No. O1, R0, Q0, J2, K4

\section{ABSTRACT}

Natural and agricultural resources for which there is a substantial black market, such as coca, opium, and diamonds, appear especially likely to be exploited by the parties to a civil conflict. On the other hand, these resources may also provide one of the few reliable sources of income in the countryside. In this paper, we study the economic and social consequences of a major shift in the production of coca paste from Peru and Bolivia to Colombia, where most coca leaf is now harvested. This shift, which arose in response to the disruption of the "air bridge" that previously ferried coca paste into Colombia, provided an exogenous boost in the demand for Colombian coca leaf. Our analysis shows this shift generated economic gains in rural areas, primarily in the form of increased self-employment earnings and increased labor supply by teenage boys. There is little evidence of widespread economic spillovers, however. The results also suggest that the rural areas which saw accelerated coca production subsequently became much more violent. Taken together, these findings support the view that the Colombian civil conflict is fueled by the financial opportunities that coca provides. This is in line with a recent literature which attributes the extension of civil conflicts to economic rewards and an environment that favors insurgency more than to the persistence of economic or political grievances.

Joshua D. Angrist

Department of Economics

MIT, E52-353

50 Memorial Drive

Cambridge, MA 02142-1347

and NBER

angrist@mit.edu
Adriana Kugler

University of Houston

Department of Economics

204 McElhinney Hall

Houston, TX 77204-5019

and NBER

adkugler@uh.edu 
"If it weren't for the armed groups, I think we could reach a consensus on what the region needs to progress. But all the armed groups want is to control the economic question, and all are willing to massacre or murder or force people from their homes to win.

-- Gloria Cuartas, major of Apartadó (quoted in Kirk, 2003).

\section{Introduction}

The consequences of changing regional economic conditions are of longstanding economic and policy interest. American examples include the fate of regions with declining industries such as coal (Black, Daniel, and Sanders, 2002; Black, McKinnish and Sanders, 2005) and, in the other direction, the Alaskan pipeline boom (Carrington, 1996). But nowhere is the interest in regional economic conditions more acute than in war-torn nations or regions embroiled in civil conflict. Perhaps not coincidentally, many such areas appear to have local economies that depend to a large extent on natural resources, especially those related to illegal economic activities or for which there is a black market. Examples include the drug trade in Latin America and Afghanistan and so-called blood diamonds in Africa. The regional concentration of these activities raises the question of whether economic activity in conflict zones sustains or dampens conflict. One possibility is that increasing income reduces poverty, thereby moderating combatants' desire to fight. But increases in the value of easily exploited economic resources may also contribute to instability and violence.

The idea that resource wealth can be bad for development is sometimes known as the "resource curse" (e.g., Sachs and Warner, 2000). Economic analyses of the resource curse typically focus on the possibilities of an export-induced Dutch disease and effects on government corruption or rent seeking (e.g., Sala-i-Martin and Subramanian, 2003; Hausmann and Rigobon, 2003). The effect of natural resources on the incidence and duration of civil wars provides a less-explored channel by which natural resources may have perverse effects. This channel features in a burgeoning political science literature, which includes empirical contributions by Collier, Hoeffler and Sodbom (2004), Fearon (2004), and Ross (2003). An antecedent in economics is the theoretical analysis by Grossman (1991). There is some circumstantial evidence that illegal resources such as drugs increase the duration of civil conflicts (Ross, 
2004), but economists and political scientists have yet to produce evidence on this question from a compelling natural experiment.

In this paper we use a quasi-experimental research design to study the impact of demand shocks for illicit resources on rural economic conditions and civil conflict. The setting for our study is Colombia, an excellent laboratory in this case since almost all of the cocaine consumed in North America and Europe comes from the Andean nations of Bolivia, Colombia, and Peru (United Nations, 2001). Moreover, we exploit a sharp change in the structure of the Andean drug industry: before 1994, most of the cocaine exported from Colombia was refined from coca leaf grown in Bolivia and Peru. Beginning in 1994, however, in response to increasingly effective air interdiction by American and local militaries, the so-called air bridge that ferried coca paste from growers to Colombian refiners was disrupted. In response, coca cultivation and paste production shifted to Colombia's countryside, where it eventually surpassed pre-interdiction levels as Colombian growers became more productive. We use this shift to assess the consequences of the coca economy for Colombia's rural population.

The first question considered here is whether increased demand for coca affected economic conditions for the rural population in ways we can measure using survey data. In particular, the end of the air bridge provides a mirror which can be used to look at the claim that drug interdiction has substantial economic costs for rural producers (see, e.g., Leons, 1997, and Chauvin, 1999). If interdiction is costly, then the post-air-bridge Colombian coca boom of the early 1990s should have had substantial economic benefits. We therefore look at effects on earnings, labor supply, and income, as well as child labor and school enrollment. Of course, coca cultivation per se may do little to enrich the cultivators, since - as with the relationship between the farmgate price of coffee and the beans we buy at Starbucks the price of raw coca leaf makes up a small fraction of the price of cocaine (Alvarez, 1995). On the other hand, most estimates suggest cocaine plays a large enough role in the Colombian economy for changes in the demand for coca to have a perceptible economic effect. ${ }^{1}$

\footnotetext{
${ }^{1}$ For example, Steiner (1998) estimates total Colombian income from illegal drugs at 4-6 percent of GDP in the first half of the 1990s. See also Thoumi (2002).
} 
The widely observed association between illicit crops and civil strife raises the related question of whether increased coca cultivation has an impact on violence. The link with violence is especially relevant in Colombia, which has experienced some of the highest homicide rates in the world in spite of substantial economic growth through most of the $20^{\text {th }}$ Century and Colombia's status as one of the oldest democracies in Latin America. The effect of the drug trade on violence has been widely debated in Colombian policy circles (see, e.g., Cardenas, 2001). While a link at first seems obvious, it bears emphasizing that the historical record is ambiguous. Marijuana became an important crop only in the 1960s and the cocaine trade began in the 1970s, with significant coca plantings appearing only in the 1990s (see, e.g., Bagley, 1998). Yet violence and civil conflict, especially outside the major cities, have been a major factor in Colombian political life since independence. During 'La Violencia' (1948-57), for example, as many as 200,000 Colombians were killed (Winn, 1999). Clearly, cocaine cannot be blamed for starting this conflict, though it may have a role in perpetuating it.

Weighing in favor of a link between the Colombian drug trade and violence is the fact that some of the more recent violence is the work of drug cartels or individuals operating on their behalf. Thus, homicide rates peaked in the late 1980s and early 1990s, when the cartel leadership rebelled against extradition efforts. Probably more importantly, the major Colombian Guerilla groups, especially the Colombian Revolutionary Armed Forces (FARC) and the National Liberation Army (ELN), are widely believed to derive substantial income by taxing drug proceeds, as do illegal self-defense groups or paramilitaries (Rangel, 2000; Rabasa and Chalk, 2001; Villalon, 2004).

Although our focus is on a Colombian case study, the links between economic activity and violence are of long-standing interest to economists. On one hand, our study provides additional evidence in the spirit of Miguel, Satyanath, and Sergenti (2004), who link exogenous changes in economic conditions (generated by rainfall) to civil conflict in Africa. As noted above, our work is also related to a growing political economy literature on the forces that generate civil conflict. Collier and Hoeffler (2004) argue that modern civil wars are sustained in large part by economic forces such as easy financing for rebel groups and the opportunity to extract rents from economic activity. Fearon and Laitin 
(2003) similarly focus on the "pull" of opportunity as opposed to the "push" of grievances in generating and sustaining conflict. ${ }^{2}$

Two broad features of our findings support the new opportunistic view. First, in contrast with the Black, Daniel, and Sanders (2005) study of coal-mining regions in the US, we find no evidence that coca substantially benefits an entire growing region. While coca cultivation is associated with increased selfemployment income for those already active in this sector, it does not raise employment or overall earnings. This is consistent with anecdotal evidence that the economic benefits of coca growing are largely taxed away by combatants or otherwise dissipated through non-productive activities. Second, in spite of the fact that coca appears to increase income and hours worked for some groups, violence increased sharply in the coca-growing regions when growing increased. This is consistent with the view that coca fuels Colombia's seemingly interminable civil conflict. ${ }^{3}$

The paper is organized as follows. The next section provides additional background and shows why a cross-country analysis of the impact of coca growing in Latin America is unsatisfactory. Section III outlines the approach we used to divide Colombia into coca-growing and non-growing regions for the purposes of our within-country survey-based analysis. Section IV discusses estimates of the effect of coca growing on rural economic conditions and Section V presents the mortality estimates. Section VI summarizes and interprets the results.

\section{Institutional Background and Economic Framework}

Coca is grown in thousands of small peasant holdings, initially mostly in Bolivia and Peru. ${ }^{4}$ Harvested coca leaves are dried by farmers and sold to entrepreneurs who make them into coca paste, a simple chemical process that takes a few days. Paste has about one-hundredth the volume of coca leaves, and the transition from leaf to paste is where most of the weight reduction in cocaine production occurs.

\footnotetext{
${ }^{2}$ A related literature contrasts opportunism and poverty as causes of terrorism; see, e.g., Krueger and Maleckova, 2003; Abadie, 2004.

${ }^{3}$ Diaz and Sanchez (2004) offer a recent exploration of the coca-conflict nexus in Colombia, arguing that conflict causes coca and not vice versa, but their spatial-correlations research design does not exploit exogenous shifts.

${ }^{4}$ This section draws on Whynes (1992) and Thoumi (1995).
} 
The next step in coca processing is to make coca base, a somewhat more complicated chemical process. Finally, cocaine hydrochloride is refined from coca base, a chemical process that often occurs in towns or cities. Street cocaine is made by diluting cocaine hydrochloride with sugar and baking soda, usually in the consuming country.

While Colombia has almost always been the principal exporter of refined cocaine, until fairly recently little coca was grown there. Colombian middlemen and exporters operated by importing coca paste (or coca base) from Bolivia and Peru, specializing in refining and distributing cocaine hydrochloride (i.e., cocaine). In the early 1990 s, the drug industry changed in response to a change in emphasis in US and producer-country enforcement policies. In April 1992, after Peruvian president Fujimori's so-called self-coup, the Peruvian military began aggressively targeting jungle airstrips and small planes suspected of carrying coca paste, as part of a general process of militarization of the drug war (Zirnite, 1998). Colombia followed suit in 1994 with a similar shoot-down policy for planes ferrying paste from both Peru and Bolivia. US policy moved in tandem with Presidential Decision Directive 14 in November 1993, which shifted U.S. interdiction away from Caribbean transit zones like Bermuda towards an attempt to stop cocaine production in the Andes. The disruption of the air bridge ferrying coca paste into Colombia was a key part of this effort. ${ }^{5}$

The militarization of the drug war and disruption of the air bridge does not appear to have reduced the supply of cocaine (see, e.g., Rabasa and Chalk, 2001). It did, however, lead to a marked shift in the organization of the industry among producer countries. This can be seen in Figure 1, which uses data from a United Nations (2001) drug report to show the change in the locus of production of dry coca leave from Peru and Bolivia to Colombia. While Bolivian production was flat in the early 1990s, Peruvian production fell sharply from 1992 to 1993, followed by a sharp increase in Colombia of about 50 percent from 1993 to 1994 . Part of this increase appears to have come from increased cultivation and

\footnotetext{
${ }^{5}$ The Peruvian and Colombian shoot-down policies can be seen as a response to U.S. pressure. Militarization of the drug war began as part of first President Bush's "Andean Strategy" in 1990, with a program of military, economic, and law-enforcement assistance for Andean nations in FY1990-94. Initially, however, this effort met with little sympathy in the region (Washington Office on Latin America, 1991). Late 1992 and 1993 marked the beginning of a period of independent efforts and sharply increased cooperation by producer nations.
} 
part from improved yields. Colombian production continued to grow thereafter, as did the Colombian share of total production. Other figures in the United Nations (2001) report show that by 1997, potential coca production in Colombia (i.e., before crop eradication following Plan Colombia in 2001) exceeded that in Peru.

\section{Economic framework}

We see the end of the air bridge as initiating an exogenous fall in the price of coca (leaf, paste, or base) in the traditional producer nations of Bolivia and Peru, while causing a price increase in Colombia. The price in traditional growing countries fell when coca could no longer be shipped to Colombian refineries and distributors. Peruvian and Bolivian growers have no competitive export channels of their own since they have no Caribbean ports and because their foreign distribution networks are not welldeveloped. At the same time, the price of coca grown in Colombia increased when drug middlemen and entrepreneurs tried to elicit new and more accessible supplies. Farmers and potential farmers responded to the increase in the price of coca by growing more of it, a response that very likely accounts for the pattern in Figure 1, though non-economic factors may have been at work as well.

Did the end of the air bridge really change coca prices in the manner described above? Although we do not have a reliable time series of coca prices by producer country, anecdotal evidence supports this description of the coca market in the mid-1990s. For example, Zirnite (1998, p. 171) quotes the regional US military commander testifying to Congress in 1996 that, "the so-called air bridge between Peru and Colombia saw a greater than $50 \%$ temporary reduction of flights," and that consequently, “. . there was a glut of coca base on the market and the price of the product being shipped fell 50 percent overall and by as much as 80 percent in some areas." On the Colombian side, data reported in Uribe (1997, p. 62) for the department of Guaviare show the price of base more than doubled from 1992-94. Journalistic accounts similarly point to an increase in prices in Colombia (e.g., Villalon, 2004). ${ }^{6}$

\footnotetext{
${ }^{6}$ A related question is why coca was not previously grown in large quantities in Colombia. The answer appears to be that Colombian coca farms were less productive; see p. 71 in Uribe (1997). Consistent with the increase in coca
} 
This framework suggests a number of channels through which increased coca cultivation might affect economic conditions and the level of rural violence in coca-growing regions. The increase in coca prices presumably made coca farmers better off, with possible regional spillovers of the sort documented by Black, McKinnish, and Sanders (2005) in the Appalachian coal-mining region and by Carrington (1996) in Alaska. Spillovers may arise here because of linkages to other sectors or due to increased demand as a result of income effects. At the same time, increased prices and production generated new sources of revenue for taxation. Because the central government is weak in the Colombian countryside, these opportunities most likely benefited guerillas and paramilitaries. Of course, if coca taxes are too high, then there is no incentive to produce. Taxes were imposed not only at the point of sale, however, but also through kidnapping, extortion, and based on the guerilla's "economic census", a sort of partisan's tax return (Rangel, 2002, p. 588). ${ }^{7}$ This tax and extortion system may transfer a large fraction of the economic benefits of coca production to combatants, while still leaving coca production more attractive than alternative activities. In addition, to the extent that coca finances a disruptive civil conflict, increased coca production may have reduced the overall level of economic activity in war-torn regions.

\section{Cross-country Comparisons}

The purpose of this paper is to assess the social and economic consequences - for Colombians of the shift in coca cultivation and the production of coca leaf and paste to Colombia. A natural starting point for this sort of analysis is a cross-country comparison. We begin with a picture of GDP growth in the Andes and neighboring countries, shown in Figure 2a. In the early 1990s, Colombian growth rates began falling, eventually becoming negative. Peruvian GDP growth fell even more steeply, after a sharp up-tick in 1993. The figure also shows, however, that many Latin American countries were in recession

production, the production of Colombian coffee, which like coca is grown mainly in small plots, turned sharply downwards in the mid-late 1990s, after increasing over most of the previous two decades (see http://www.dane.gov.co/inf est/ena.html).

${ }^{7}$ About $85 \%$ and $65 \%$ of the FARC's and ELN's revenues, respectively, are estimated to come from drugs and extortion (Rangel, 2002, p. 585). While similar estimates of revenue sources do not exist, paramilitary groups are also widely believed to benefit from the drug trade. Grossman and Mejia (2004) develop a theoretical model of guerilla involvement in drug production. 
to one degree or another for much of the 1990s. By contrast, Bolivia's GDP was mainly constant throughout the 1990s. The fact that GDP growth declined more steeply in Peru than in Colombia may be due in part to the shift of coca production to Colombia. Nevertheless, the figure also suggests the presence of strong country-specific trends that may dominate these effects.

Paralleling our interest in violence and civil conflict, Figure $2 \mathrm{~b}$ plots homicide rates by country in Latin America for 1990-2001 or years where data are available. In contrast with a pattern of generally increasing homicide in the 1980s, (see, e.g., Gaviria, 2000), the Colombian homicide picture was largely improving in the 1990s. While rates also fell in Bolivia (over the brief period for which we have data) and over a longer period in Peru, homicide in Colombia began to decline in 1992, and fell steeply after 1993, when coca production was skyrocketing. At the same time, the homicide picture in other comparison countries, such as Brazil, Ecuador, and Venezuela was stable or deteriorating. Again, the cross-country differences in trend are difficult to interpret; the early 1990s saw extraordinary violence as Colombian drug lords fought amongst each other and with the government, mainly in urban areas and largely in reaction to US pressure for extradition. The death of Pablo Escobar in December 1993 marked the end of what was an unusually violent period, even by Colombian standards. The strong countryspecific trends in violence suggest that here too a within-country analysis, distinguishing urban and rural violence, is likely to be more fruitful.

\section{Classification of Regions}

Our research design exploits the fact that the change in the drug industry in the early 1990s probably had a disproportionate effect on Colombian departments which, by virtue of climate and soil conditions, politics, or infrastructure were hospitable to the cultivation of coca plants and the production of coca paste. This naturally raises the question of how to classify departments or regions as potential coca-growers and paste-producers. The best candidates for future coca production seem likely to be departments with a pre-existing coca presence. We identified baseline coca-growing departments using estimates for 1994 reported in Uribe (1997, p. 67). This source collects a number of international 
observers' estimates of hectares of coca bush under cultivation in Colombian departments. The reports summarized in the table are dated October 1994, so the data were presumably collected somewhat earlier. The 9 departments that had at least 1,000 hectares under cultivation are Bolivar, Caqueta, Cauca, Meta, Narino, Putumayo, Guaviare, Vaupes, and Vichada. ${ }^{8}$

In a second coding scheme, we expanded the definition of the growing region to include the five additional departments identified as growing on a satellite map in Perafan (1999, p. 11). This map is also dated 1994. The Perafan map adds the three Northern departments of Cesar, Magdalena, and La Guajira, and the departments of Norte de Santander and Guainia. These 5 are also listed as growing regions in Uribe (1997), while all in the group of 9 appear as growing on Perafan's (1999) map. We refer to the expanded coding scheme as defining a "14-department growing region" and the 5 additional departments added to the 9 growing departments to construct this region as "medium producers".

Our color-coded map, reproduced in the Appendix, shows the 9 department growing region to be concentrated in the Southern and Eastern part of the country. Note, however, that not all Southern or Eastern departments grow large amounts of coca. For example, Amazonas, in the Southeast corner, and Arauca, in the East, are not coded as a growing department in either scheme. The group of 9 growing departments includes two, Meta and Caqueta, which were ceded to FARC control from 1998 to 2001 as part of an abortive peace effort. We refer to these two as the demilitarized zone (DMZ) and allow for separate DMZ effects in the empirical work. The five departments coded as medium producers are mostly in the Northern part of the country, though one, Guainia, is in the far Eastern region.

To establish a "first-stage" relation for our division of Colombian departments into growing and non-growing regions, we regressed the growth in coca cultivation from 1994 to 1999 or 1994 to 2000 on an indicator for growing status in 1994. Growth is measured from a 1994 base since this is the year used to classify growing regions (as noted earlier, the 1994 data were probably collected earlier). The endpoint years of 1999 and 2000 are used because these are the years for which departmental cultivation

\footnotetext{
${ }^{8}$ Black, McKinnish, and Sanders (2002) similarly identify counties affected by the coal boom and bust using preexisting production data.
} 
figures are available. In any case, the change from 1994 to the end of the decade seems likely to provide a good summary of coca penetration in the relevant period. ${ }^{9}$

The first-stage results, summarized in Table 1, show a strong correlation between coca growth and base-period growing status. ${ }^{10}$ The estimates in Column (1), Panel A indicate that cultivation grew by about 8,000 more hectares in the 9-department growing region than elsewhere, while the omission of medium producers leads to a slightly larger effect. Omission of the two DMZ departments leads to an even larger effect of almost 9,000 hectares, shown in column 2 of Panel B. With or without DMZ departments, the growth effect is significantly different from zero. The estimates in Columns (5)-(8) also show mostly larger effects when growth is measured through 2000 instead of 1999, with growing regions gaining 8,961 (s.e. $=4,358$ ) hectares over the period in the sample without medium producers. ${ }^{11}$ None of the intercept estimates are significantly different from zero, indicating essentially no growth in the departments with no initial production in 1994. Finally, estimates with growing status defined using the 14-department scheme, i.e., moving the medium producers to the treated group, also show substantial growth in cultivation, but less than in the 9-department subset omitting medium producers. The 14department scheme also generates a smaller intercept.

An interesting finding in this context, relevant for our choice of estimation strategy, is that dummies for the two growing regions do a better job of predicting coca growth than a linear predictor using base-period levels. Results from the linear parameterization can be seen in the last two rows of each panel of Table 1. A visual representation of alternate parameterizations is presented in Figure 3,

\footnotetext{
${ }^{9}$ The 1999-2000 data are from Colombia's anti-drug agency, Direccion National de Estupefacientes (DNE, 2002), collected through the Illicit Crop Monitoring System (SIMCI- Sistema Integrado de Monitoreo de Cultivos Ilicitos). This system was implemented by the United Nations Office on Drugs and Crime with the logistical support of the Colombian anti-narcotics Police (DIRAN) and in coordination with the DNE. The data are from satellite images and verification flights. Data for 2000 appear to be more complete than the 1999 data.

${ }^{10}$ Our use of the term "first-stage" in this context is motivated by the fact that, given consistent departmental time series data on coca production, we could use interactions between initial growing conditions and a post-air-bridge dummy as an instrumental variable for the effects of endogenous coca production on economic conditions and violence. In the absence of reliable data on the relevant endogenous variable, we focus below on the reduced form regressions of economic and mortality outcomes on initial conditions/time interactions.

${ }^{11}$ Mean growth is about 2,800 hectares through 1999 and 2,900 through 2000. The 1994 mean for hectares under cultivation is about 2,100. In the 9-department growing region, the base mean was 7,155 and the in 14-department growing region, the base mean was 4,732 .
} 
which plots coca growth against base period levels, using different symbols for the non-growing region, the 9-department growing region, and the remaining growing region on a log scale. The two growing regions have much higher coca growth, but the relationship between base period levels and growth rates is not especially linear. Although the best single predictor of coca growth is a dummy for the 9department region, the empirical work below focuses mainly on the 14-region scheme since this turns out to balance pre-treatment homicide rates better than the 9-department scheme and because the rural household survey is missing some growing departments. ${ }^{12}$

\section{Descriptive Statistics by Region Type}

Not surprisingly, the growing departments are more rural than the rest of the country. This is apparent in the descriptive statistics in Table 2, which compares growing and non-growing regions along a number of dimensions. The comparison between growing and non-growing is affected by the fact that the non-growing region includes the three departments with Colombia's largest cities: the Bogota capital district; Antioquia, which contains Medellin, an especially violent city; and Valle del Cauca, where Cali is located. To improve comparability with growing regions when comparing homicide rates, we tabulated statistics without these 3 departments. We also drop the Bogota capital district, Antioquia and Valle del Cauca from the mortality analyses in order to avoid confounding the effects of coca production with the secular decline in violence in big cities in the early nineties. Only the Bogota capital district is dropped from the analysis of rural labor markets and rural income.

Omitting the 3 big-city departments, the non-growing population is 65 percent urban, in comparison to 50 percent urban in the 9 department region minus the $\mathrm{DMZ}, 58$ percent in the $\mathrm{DMZ}$, and 66 percent urban in the 5 additional growing departments (medium producers). Although growing and non-growing departments differ along the urban/rural dimension, they had similar primary school

\footnotetext{
${ }^{12} \mathrm{We}$ also attempted to define growing regions based on climate and soil conditions using geographic information from Torres and Mendez (2000). In practice, this did not lead to as strong a first stage for coca growth as a classification schemes based on 1994 levels, probably because coca appears to be a hardy plant that grows under a fairly broad range of conditions (Thoumi, 2002, p.105).
} 
enrollment rates. Secondary school enrollment was somewhat lower in the growing regions, consistent with the fact that these regions are more rural.

The early 1990s homicide rates shown in the table were unusually high, even by Colombian standards. For example, the homicide rate reached a remarkable 719 per 100,000 in Antioquia, mostly because of violence in Medellin, and was 272 overall in the non-growing region. These statistics are per 100,000, among men aged 15-59. Without the big-city departments, homicide rates in the non-growing region averaged 141 per 100,000. This can be compared to the rates of 87 in the 9-department growing region without the DMZ, 151 in the medium producers, and 205 in the DMZ. Thus, omission of big-city departments makes homicide rates somewhat more comparable across regions.

\section{Potential Confounding Factors}

A potential complication for our analysis is the fact that many growing departments became centers of insurgent activity, perhaps for reasons unrelated to the expansion of the coca industry. At the beginning of the decade, however, fewer growing departments were guerilla strongholds. This can be seen in the 1990 distribution of homicides by department (Ministerio de Defensa Nacional, 2001, p. 24). Although homicide is not synonymous with a guerrilla presence, a link is widely drawn (e.g., Cardenas, 2001; Rangel, 2000). ${ }^{13}$ In an attempt to separate coca-induced effects, including those related to insurgent activity, from the direct effect of a strong guerilla presence, we estimate models with separate effects for the DMZ, where the FARC presence is likely strongest, and for the rest of the growing region.

Another relevant consideration in the Colombian context is the large number of economic migrants who move to rural areas in search of work (e.g., in the coca fields) and especially the flow of refugees out of the countryside as a consequence of the civil conflict ("poblacion desplazada"). Both types of migration may induce selection bias in an analysis of economic circumstances in rural areas with

\footnotetext{
13 A study by the Federal Research Division (1988) of the Library of Congress identifies guerilla strongholds in 1988 as falling in the departments of Huila, Caqueta, Tolima, Cauca, Boyaca, Santander, Antioquia, Valle del Cauca, Meta, Cundinamarca and Arauca. Of these, we classify Huila, Tolima, Boyaca, Santander, Antioquia, Valle de Cauca, Cundinamarca, and Arauca as non-growing, Cauca as growing, and Caqueta and Meta as growing, DMZ. See also Figure 4.2 in Rabas and Chalk (2001), which shows the strongest FARC presence in and around the DMZ in 1986-87, though areas of FARC activity subsequently expanded to cover most of the country (Figure 4.3).
} 
many in- and/or out-migrants. As a partial check on the first issue, we report results from samples with and without migrants. It is also worth noting that much displacement occurs within departments, and that, according to United Nations High Commission for Refugees (UNHCR, 2002), the largest senders and receivers of displaced populations include both growing and non-growing departments under our classification scheme, while the phenomenon of internal displacement long pre-dates the rise in coca production. In fact, a specification check which looks for growing-region/year interactions of the sort that might confound our analysis shows no growing/post-1995 effect on the probability of being a migrant.

\section{The Economic Consequences of a Coca Economy}

\section{Data and Descriptive Statistics}

This section uses differences-in-differences type regressions to assess the economic consequences of the shift in coca production to Colombian growing regions. The data come from the rural component of Colombia's annual household survey and are described in the Appendix. The rural survey provides large repeated cross-sections, with information on households and individual household members, including children. We limit the analysis to data from 1992 (because of earlier changes in survey design) through 2000 (after which the survey was replaced by a new panel data set). The survey was conducted in 23 of Colombia's 33 departments. ${ }^{14}$ Using the 14-department definition of the growing region, the rural survey includes households from 7 growing departments plus the two DMZ departments. Because only 3 non-DMZ departments from the 9-department growing region were included in the rural survey, we focus initially on the 14-department classification scheme.

Our analysis looks separately at samples of adults, school-age children, and teenage boys who might be in the labor market. The sample of adults includes men and women aged 21-59, and is described in the first two columns of Table 3 using data for 1992 and 1997 . Roughly $30 \%$ of respondents

\footnotetext{
${ }^{14}$ The included growing departments are Bolivar, Cauca, Narino in the 9-department region, plus Cesar, La Guajira, Magdalena, and Norte de Santander, plus Caqueta and Meta in the DMZ. In contrast with the mortality analysis, Antioquia and Valle de Cauca are included in the non-growing sample because the survey is limited to rural households.
} 
in this sample were migrants, where migrants are defined as individuals who do not currently live in the county where they were born. Most were married and about half are male. The growing region contributed from 24 percent of the sample in 1992 to 30 percent of the sample in 1997. The number of respondents from the DMZ also increased, from 1.4 to 3.9 percent. Not surprisingly, few of the adults were enrolled in school.

About two-thirds of adults in the survey were employed in 1992 and 1997, though only about 36 percent had positive wage and salary earnings. Employment rates for men were 93-95 percent, as can be seen in Columns (3) and (4), and 55 percent of men had positive wage and salary earnings. Between 25 and 26 percent of adult men and women had positive income from self-employment, while between 35 and 37 percent of adult men had positive income from self-employment. Self-employment income includes income from individual short-term contracts, from the sale of domestically produced goods, and from commercial or family-based agricultural production. Wage and salary earnings and selfemployment income are reported in real terms and were constructed using the consumer price index provided by the Department of National Statistics (DANE). These variables are given in 1998 pesos, worth about 1,400 to the US dollar. Thus, mean wages range from 52 to 77 dollars per month, and mean self-employment income from 241 to 398 dollars per year, in the sample of adults.

Descriptive statistics for the sample of children, reported in Columns (5)-(8), show that most were enrolled, and enrollment rates increased somewhat between 1992 and 1997. Fewer children than adults were migrants, but the regional distribution of children was broadly similar to that for adults. Employment statistics for children are only collected for those over 10 years of age. About a third of boys aged 10-16 and 10 percent of girls aged 10-16 were working, indicating the importance of child labor. The statistics in Columns (9) and (10) show that over half of boys aged 13-20 were working. Hours per month for boys were substantial, though lower than for adults. Boys also had lower earnings. The wage and salary income of boys ranges from 42-44 dollars per month, and boys' self-employment income ranges from 44-47 dollars per year. Less than half were still enrolled in school and few were married. 
Results for Adults

The basic empirical framework looks for growing-region/post-air-bridge interactions while controlling for department and year effects. In particular, we estimated year-region interaction terms using the following model for respondent $\mathrm{i}$ in department $\mathrm{j}$ in year $\mathrm{t}$ :

$$
\mathrm{y}_{\mathrm{ijt}}=\mathrm{X}_{\mathrm{i}}^{\prime} \mu+\beta_{\mathrm{j}}+\delta_{\mathrm{t}}+\Sigma_{\mathrm{s}} \alpha_{0 \mathrm{~s}} \mathrm{~g}_{\mathrm{js}}+\Sigma_{\mathrm{s}} \alpha_{1 \mathrm{~s}} \mathrm{~d}_{\mathrm{js}}+\varepsilon_{\mathrm{ijt}}
$$

where $\beta_{\mathrm{j}}$ is a department effect, $\delta_{\mathrm{t}}$ is a year effect, $\mathrm{g}_{\mathrm{js}}$ indicates non-DMZ growing departments when $\mathrm{t}=\mathrm{s}$, and $\mathrm{d}_{\mathrm{js}}$ indicates DMZ departments when $\mathrm{t}=\mathrm{s}(\mathrm{s}=1994, \ldots, 2000)$. The parameters $\alpha_{0 \mathrm{~s}}$ and $\alpha_{1 \mathrm{~s}}$ are the corresponding region-type/year interaction terms. Some models also include linear trends for each department type as a control for omitted variables and serial correlation. This amounts to replacing $\beta_{\mathrm{j}}$ with $\beta_{0 \mathrm{j}}+\beta_{1 \mathrm{j}}$ t, where $\beta_{1 \mathrm{j}}$ takes on 3 values (non-growing, growing, and DMZ). The estimating equations also control for a vector of individual covariates, $\mathrm{X}_{\mathrm{i}}$, which includes sex, age dummies, household size, marital status and migrant status. For binary dependent variables, the linear model was replaced with the analogous logit.

The analysis of rural outcomes begins with estimates of effects on the probability of having selfemployment income and on the log of self-employment income for those who have some. Because coca production is an agricultural activity, self-employment status (either as farmer, employer, landowner, or contractor) is of special interest. The interpretation of results for log self-employment income is potentially complicated by selection bias from conditioning on having earnings in this sector. As in a wage equation, however, we can make an educated guess as to the likely sign of any selection bias. Since the presumptive effect of being in the growing region after 1994 is to increase the likelihood of selfemployment, the conditional-on-positive estimates of effects on log wages will typically be biased downwards by the fact that, on the margin, those induced to enter self-employment have lower selfemployment earnings potential in the absence of treatment (see, e.g., Angrist, 2001).

The first two columns of Table 4a report marginal effects from the logit version of equation (1), with a dummy for self-employment status on the left-hand side. The sample includes women as well as men because women have a reasonably high probability of having self-employment income. The 
estimates in Column (1) are small, with positive but insignificant effects in 1996-97 and 1999-00. We also report results without migrants as a partial control for potential selection biases from migration into and out of growing regions. Results omitting migrants, reported in Column (2), are somewhat larger, showing a marginally significant positive effect in $1996(0.049$, with an s.e. of 0.03$)$ and a significant effect of 0.052 in 2000 (s.e. $=0.022) .{ }^{15}$

In contrast with the small-to-zero estimates for self-employment probabilities, the estimates in Columns (3) and (4) show a substantial increase in (log) self-employment income. In particular, there are large, statistically significant effects on the order of 0.3-0.4 in 1996-98, a period when coca is likely to have had a major impact. For example, the effect in 1996 in the sample including migrants is 0.362 (s.e. $=0.131)$. There are somewhat smaller positive effects in 1995 and 1999-2000, the former not significantly different from zero and some of the latter marginally significant.

In an effort to improve precision, we also estimated models with pooled region-year interaction terms. These models can be written

$$
\begin{aligned}
\mathrm{y}_{\mathrm{ijt}}=\mathrm{X}_{\mathrm{i}}{ }^{\prime} \mu & +\beta_{\mathrm{j}}+\delta_{\mathrm{t}} \\
& +\alpha_{0,95-97} \mathrm{~g}_{\mathrm{j}, 95-97}+\alpha_{0,98-00} \mathrm{~g}_{\mathrm{j}, 98-00}+\alpha_{1,95-97} \mathrm{~d}_{\mathrm{j}, 95-97}+\alpha_{1,98-00} \mathrm{~d}_{\mathrm{j}, 98-00}+\varepsilon_{\mathrm{ijt}},
\end{aligned}
$$

where $X_{i}$ is the vector of individual characteristics referred to above, with coefficient vector $\mu$. The interaction dummies $\mathrm{g}_{\mathrm{j}, 95-97}$ and $\mathrm{g}_{\mathrm{j}, 98-00}$ indicate the non-DMZ growing region for $\mathrm{t}=1995-97$ and $\mathrm{t}=1998$ 2000 , with corresponding interaction terms $\alpha_{0,95-97}$ and $\alpha_{0,98-00}$. Likewise, the interaction dummies $\mathrm{d}_{\mathrm{j}, 95-97}$ and $d_{j, 98-00}$ indicate the DMZ in 1995-97 and 1998-2000, with corresponding interaction terms $\alpha_{1,95-97}$ and $\alpha_{1,98-00}$. As before, with binary dependent variables the reported results are logit marginal effects. Also, as with equation (1), we estimated versions of (2) replacing $\beta_{\mathrm{j}}$ with $\beta_{0 \mathrm{j}}+\beta_{1 \mathrm{j}}$ t, where $\beta_{0 \mathrm{j}}$ is a department fixed effect and $\beta_{1 \mathrm{j}}$ is a trend taking on 3 values, one for each department type.

Self-employment results from models with pooled interaction terms and omitting trends are reported in Columns (1) and (3) of Table 4b. These models generate statistically significant estimates of

\footnotetext{
${ }^{15}$ Standard errors were adjusted for random/group effects at the department-year level. Rural estimates with department-only clustering are similar. Because there are relatively few clusters (departments) we prefer the department-year clustering scheme.
} 
effects on the probability of self-employment and on the log of self-employment income in the non-DMZ growing region. The former effects are small, on the order of 3-4 percentage points, but the latter are large (see, e.g., the Column (3) estimate of 0.25 in 1995-97 with a standard error of 0.1). Moreover, the absence of substantial effects on the probability of having self-employment income suggests selection bias from changes in labor force participation is not much of a concern in this context.

Estimates of interactions for the DMZ show no effect on the probability of having selfemployment income, but even larger (though imprecisely estimated) effects on log self-employment income than in the non-DMZ region. Again, these results may be subject to selection bias as a result of migration, especially in the DMZ, though we include a migrant dummy as a partial control. At the same time, as pointed out above, we found no evidence of selection bias due to migration in a regression of the probability of being a migrant on a growing/post-1995 interaction.

The evidence for an effect of the coca boom on the probability of self-employment is weakened considerably by the inclusion of region-specific trends. For example, the estimates reported in Column (2) of Table $4 \mathrm{a}$ are either zero or negative. On the other hand, the 1995-97 effect on the log of selfemployment income, estimated in a model with region-specific trends, is about the same as when estimated without trends (compare 0.288 and 0.251$)$ and close to significant at the 0.1 level $(\mathrm{t}=1.47)$. Moreover, the trend itself is not significantly different from zero.

The remaining estimates in Tables $4 \mathrm{a}$ and $4 \mathrm{~b}$ are for effects on labor supply measures and the log of monthly wages in a sample of men. We focus on men because male participation rates are considerably higher than female participation rates, especially in the wage sector. The estimated employment effects for men show little evidence of a change in participation in the growing region. Most of the estimated interaction terms are small and none are significantly different from zero. There is some evidence of an increase in log hours, though it is not very robust. For example, in the hours equation, the 1996 interaction without migrants is 0.048 (s.e. $=0.033$ ) and the 1998 interaction with migrants is 0.053 (s.e. $=0.02$ ). In models with pooled interactions, there is stronger evidence for a significant effect in 19982000 than in 1995-97, though again the estimates are muddied by inclusion of region-specific trends. 
The estimates for the log wage outcome also show evidence of some effects in 1998-2000, though not in 1995-97. In particular, the strongest effects on wages are in 1998 and 1999. For example, yearly interactions in models with and without migrants are a significant 10-11 percent in 1998 and a significant 7 percent in 1999. The increase in relative wages in the growing region in 1998 and 1999 is noteworthy given the high levels of violence in the same period. Effects in the later period but not the earlier may be indicative of a delayed spillover from the coca boom, but they may also reflect the continuation of some other regional trend. The fact that the log wage effects for 1998-99 disappear in models with regionspecific trends (see Column (10) in Table 4b) points to the latter possibility.

\section{Results for Children and Youth}

We might expect the increase in coca production to have reduced school enrollment and to have generated an increase in child labor. ${ }^{16}$ Columns (1) and (2) in Table 5a indeed show statistically significant reductions of 0.065 and 0.073 in boys' school enrollment in 1997, but estimates for other years are smaller, and none of the corresponding estimates in pooled models, with or without trends, are significant (see Table 5b). Moreover, while the estimated interaction terms without trends are all negative, inclusion of trends causes the signs to flip for boys. Estimates for girls are mainly positive, though not significant. An exception is the DMZ, where effects are negative and marginally significant without trends. $^{17}$

While there appears to have been little impact on school enrollment, the pattern of estimates for teen boys' labor supply is more complex. For the non-DMZ growing region, the one-year employment effect in 1997 and the pooled later-period employment effect are positive. On the other hand, the pooled interaction term for the later period is negative and significant for the DMZ, a result that is also robust to the inclusion of trends (though these negative effects become implausibly large). The pooled non-DMZ

\footnotetext{
${ }^{16}$ Edmunds and Pavcnik (2004) recently explore the link between trade flows and child labor. Following their taxonomy, coca can be seen as an unskilled-labor intensive good that is a candidate for production with child labor.

${ }^{17}$ To adjust inference for within-household clustering, estimates for children and youth were averaged up to the household level. For details, see the Appendix.
} 
growing effects are also negative (though insignificant) when estimated in models with trends. Hence, there is no robust evidence of an increase in boys' employment rates.

Results for log hours are more clear-cut. In models without trends, log hours appear to have increased in both the non-DMZ growing region and the DMZ. For example, the pooled estimate for the earlier period for the non-DMZ area is $0.112($ s.e. $=0.048)$ and many of the yearly interactions in Table $5 \mathrm{a}$ are significant. Inclusion of trends wipes out the DMZ effect but leaves the non-DMZ effects essentially unchanged, though no longer significant. Again, however, the trend in the non-DMZ growing region is zero $(-0.0016$, s.e. $=0.022)$. On balance, therefore, Table $5 \mathrm{~b}$ provides support for the notion that coca production increased teen boys' labor supply, at least in the growing departments outside of the DMZ.

\section{Estimates Using Urban Controls and Without Medium Producers}

Although estimates of equations (1) and (2) point to effects on self-employment income for adults and effects on hours worked by teenage boys, these results are made less precise by the inclusion of region-specific trends. In an effort to increase precision and further check the robustness of these findings, we tried a pooled analysis that stacks urban with rural data for the subset of departments included in both surveys. ${ }^{18}$ The idea here is to check whether growing region/post-air-bridge interaction effects are indeed larger in rural than urban parts of growing departments, since we expect income shocks generated by coca to be larger in the countryside. An urban-rural stack also facilitates control for regionspecific trends, assuming these have similar effects in urban and rural areas. A second modification explored in this context is to drop the 5 medium producer departments from the list of 14 growing regions. In the spirit of Black, Daniel, and Sander's (2002) analysis of coal-producing counties according to the level of baseline production, this may sharpen the growing/non-growing contrast.

The estimating equation for the stacked sample allows for urban main effects and urban interactions with both region-type and period dummies in a pooled model similar to the one used to

\footnotetext{
${ }^{18}$ The urban household survey is distinct from the rural survey and has somewhat different geographic coverage and variable definitions. For details, see the Appendix.
} 
construct the estimates reported in Table $4 \mathrm{~b}$. The coefficients of interest are growing-region/posttreatment interaction terms, which are allowed to differ by urban-rural status. Because one of the DMZ departments is missing from the urban survey, we drop the other DMZ department as well and look at interactions for the non-DMZ growing region only. Finally, these models control for region-specific trends, which are assumed to be the same in both the rural and urban areas of a given department type. The addition of urban data potentially allows us to estimate these trends more precisely. The stacked analysis is limited to the subset of adult and children outcomes of primary interest and/or for which their appeared to be some evidence of effects in Tables 4 and 5 .

Estimates from the urban/rural stack for adult self-employment outcomes, reported in Columns (1)-(4) of Table 6, are similar to those generated using rural data. Again, there is no evidence of an increased likelihood of self-employment in cities or the countryside (in fact there is a negative effect for 1998-2000 in urban areas). At the same time, however, the stacked results show a sharp increase in log self-employment earnings for rural workers; in Column (3), for example, the effect is 0.29 (s.e. $=0.16$ ) in 1995-97. In contrast, the corresponding urban effect is an insignificant 0.16 (s.e. $=0.13$ ). The interaction terms in Column (3) for the $1998-2000$ period similarly show larger effects in rural than urban areas. Estimates of effects on log self-employment income using a sample without medium producers are slightly larger than in the full sample, but otherwise similar.

In contrast with the self-employment results, the estimated effects on hours worked are more mixed. Estimates with medium producers included, reported in Column (5), show no significant rural or urban effects. On the other hand, dropping the medium producers leads to significant rural and urban effects. The rural effect is larger but not significantly different from that in urban areas, so if the urban effect is taken as a check for confounding factors this would point to an interpretation of no effect on adult hours in rural areas. At the same time, Columns (7)-(8) show no effect on wage and salary earnings in either urban or rural locations.

A clearer picture emerges from the analysis of hours worked by teen boys. These results, reported in Columns (9)-(10) of Table 6, show mostly significant effects with or without medium 
producers. The results for teen boys also generate a significant contrast by urban-rural status. In particular, there are substantial increases in hours worked by rural teen boys, with no corresponding effect on teen boys in urban areas. For example, the effect on hours worked in $1995-97$ is $0.12($ s.e. $=0.07)$ in rural areas, but $-0.01($ s.e. $=0.02)$ in urban areas. Finally, we note that estimates for employment status corresponding to those in Table $4 \mathrm{~b}$ show no effects on either adult men or teen boys.

\section{Discussion of Magnitudes}

The results in Table 6 provide consistent evidence of an increase in self-employment income and hours worked by teen boys in the rural parts of coca-growing departments. To get a sense of whether the magnitude of self-employment earnings effects in Columns (3)-(4) of Table 6 can plausibly be attributed to a coca boom, we take 0.2 as a benchmark, a number between the rural effect of 0.29 from Column (3) and the corresponding difference in urban and rural effects, $0.29-0.16=0.13$. To calibrate, we use Uribe's (1997) description of a typical family coca farm, consisting of a half-hectare plot that generates about 110,000 pesos/month in revenues from the sale of coca leaf. Our estimates imply an increase in monthly self-employment earnings of about 22,800 pesos at the mean positive self-employment income for selfemployed workers (roughly 114,000 pesos per month). We do not know how many self-employed workers were actually growing coca. But assuming a quarter of self-employed adults in rural growing regions had small coca plots, an aggregate increase of $20 \%$ in self-employment earnings could have been generated by a $40 \%$ increase in output among existing producers jointly with a $40 \%$ increase in prices. This is obviously just a rough guess. The point is that the magnitude of the price increase and the earnings from coca at baseline are very likely large enough to sustain the kind of impact suggested by our estimates.

\section{Coca and Violence}

The estimates in the previous section suggest some localized benefits from the coca boom. The benefits are largely those that might be expected to accrue to farmers or others involved in the coca 
industry, including a marginal labor force of teenage boys. There is little evidence of wider spillovers. In this section we turn to an analysis of coca effects on violence, as captured by changing homicide rates.

\section{Graphical Analysis}

The evolution of violent death rates in the 1990s is described in Figure 4a, which plots death rates per 100,000 for men aged 15-59 by region type, after removing group means. This figure pools the DMZ with other growing departments defined using the 14-department scheme. ${ }^{19}$ The resulting plot shows a remarkably parallel evolution of violent death rates in the growing and non-growing areas through 1993. In particular, the growing and non-growing regions both exhibit a similar up-then-down pattern. But death rates in the growing region flattened in 1994, while the decrease in the non-growing region accelerated. Violent death rates increased in both regions after 1995, but the average rate of increase in the growing region was much steeper. In contrast with this parallel-then-divergent pattern in violent death rates, death rates from disease fell somewhat more steeply in the growing than in the non-growing region from 1990 through 1998, when there was a sharp upturn in the growing region. The evolution of death rates from disease can be seen in Figure $4 b{ }^{20}$

Figures $5 \mathrm{a}$ and $5 \mathrm{~b}$ draw a similar picture in the context of a 3-region analysis that separates the DMZ from other growing departments. Here too, violent death rates in the non-DMZ growing region flatten in 1994 after an up-then-down pattern paralleling that in the non-growing region. The main difference between this picture and that in Figure $4 \mathrm{a}$ is that violent death rates in the DMZ continued to

\footnotetext{
${ }^{19}$ The non-growing region omits Antioquia, Valle de Cauca and Bogota, the departments with Colombia's three largest cities. Deaths rates were coded from vital statistics micro data obtained from the Colombian statistical agency, DANE. Violent deaths are defined here as homicides, suicides, deaths from military and insurgent activity (not a distinct category in all years), and a small number of non-accident deaths by external causes not elsewhere classified. Over $90 \%$ of violent deaths are homicides. For additional details see the data Appendix.

${ }^{20}$ Competing risks complicate the interpretation of the decline in disease death rates since some of those who die by violence may have otherwise died of disease. Still, it seems likely that an environment of deteriorating public health would turn up in higher disease death rates (a pattern observed in the DMZ after the government ceded control). The competing risks problem is likely mitigated by the fact that those most likely to die from disease (the very old and very young) are least likely to die by violence. As a check on this problem, we looked at infant and child mortality by region type. These data also show relative improvement in the growing region until 1998. In a related inquiry, Urdinola (2003) reports results of a regression of infant mortality rates on measures of violence. It should be noted, however, that changes in definitions make the data on infant deaths in the later period hard to interpret.
} 
fall through 1995, after which they increased sharply until a 1998 peak. In contrast with the acceleration in violent death rates, death rates from disease improved steadily in the growing region relative to the non-growing region beginning in 1992. Death rates from disease in the DMZ also tracked rates in the non-growing region until 1998.

A possible complication in the analysis of death rates is the quality of the population statistics used for the denominator. We used census-based 5-year estimates and population projections published by DANE (1998) for 1990, 1995, and 2000, linearly interpolating statistics for the in-between years. The underlying census was conducted in 1993. As noted above, however, the 1990s were marked by considerable population movement so the population denominator may be inaccurate. An alternative strategy which avoids this problem is to look at violent death rates relative to death rates from other causes. After transformation to log odds, this approach can be motivated by a multinomial logit model for the risk death by cause, where survival is the reference group.

To describe the logit strategy more formally, let $\mathrm{v}_{\mathrm{jt}}$ denote the number of violent deaths in department $\mathrm{j}$ and year $\mathrm{t}$ and let $\mathrm{n}_{\mathrm{jt}}$ denote the number of deaths from all other causes. Let $\mathrm{p}_{\mathrm{jt}}$ denote the corresponding population statistics. Write the probability of violent and non-violent death as

$$
\begin{aligned}
& \mathrm{v}_{\mathrm{jt}} / \mathrm{p}_{\mathrm{jt}} \equiv \exp \left(\alpha_{\mathrm{jt}}(\mathrm{v})\right) /\left[1+\exp \left(\alpha_{\mathrm{jt}}(\mathrm{v})+\exp \left(\alpha_{\mathrm{jt}}(\mathrm{n})\right],\right.\right. \\
& \mathrm{n}_{\mathrm{jt}} / \mathrm{p}_{\mathrm{jt}} \equiv \exp \left(\alpha_{\mathrm{jt}}(\mathrm{n})\right) /\left[1+\exp \left(\alpha_{\mathrm{jt}}(\mathrm{v})+\exp \left(\alpha_{\mathrm{jt}}(\mathrm{n})\right] .\right.\right.
\end{aligned}
$$

These are identities that define $\alpha_{\mathrm{jt}}(\mathrm{v})$ and $\alpha_{\mathrm{jt}}(\mathrm{n})$. We assume further that $\alpha_{\mathrm{jt}}(\mathrm{v})$ can be modeled as an additive function of region $\left(\mathrm{B}_{\mathrm{j}}\right)$ and year $\left(\Delta_{\mathrm{t}}\right)$ effects plus growing-region/year interaction terms induced by the shift of coca production to Colombia, while $\alpha_{\mathrm{jt}}(\mathrm{n})$ has additive effects only. Then non-zero estimates of the interaction terms $\pi_{0 \mathrm{~s}}$ and $\pi_{1 \mathrm{~s}}$ in the grouped-logit equation

$$
\ln \left(\mathrm{v}_{\mathrm{jt}} / \mathrm{n}_{\mathrm{jt}}\right) \equiv \alpha_{\mathrm{jt}}(\mathrm{v})-\alpha_{\mathrm{jt}}(\mathrm{n})=\mathrm{B}_{\mathrm{j}}+\Delta_{\mathrm{t}}+\Sigma_{\mathrm{s}} \pi_{0 \mathrm{~s}} \mathrm{~g}_{\mathrm{js}}+\Sigma_{\mathrm{s}} \pi_{1 \mathrm{~s}} \mathrm{~d}_{\mathrm{js}}+v_{\mathrm{jt}}
$$

provide evidence of a region-specific shock that increased the risk of violent death.

This strategy is illustrated in Figure 6, which plots the residual from a regression of $\ln \left(\mathrm{v}_{\mathrm{jt}} / \mathrm{n}_{\mathrm{jt}}\right)$ on region effects (i.e., deviations from group means) using the 14-department classification scheme, 
separating the DMZ from other growing departments as in Figure 5. The logit plot shows the same initial pattern of up-then-down log-odds of violent death in both growing and non-growing regions, with a more stable then increasing pattern of log-odds of violent death in the growing region after 1993. This is roughly similar to the pattern exhibited by log death rates in Figure 5a. The log-odds of violent death in the DMZ also turned sharply upwards in 1995.

On balance, the figures suggest that beginning sometime between 1994 and 1996, violent death rates in the non-DMZ growing region became markedly higher than what should have been expected based on pre-1994 trends. The pattern is broadly similar in the DMZ, where the FARC presence was strongest. Moreover, the increase in violent death rates contrasts with a gradually improving disease environment in this period, both nationwide, and in the growing relative to the non-growing region. The contrast in trends for violence and disease mortality weighs against the notion of a secular deterioration in infrastructure or social systems that caused the increase in violence.

\section{Regression Estimates}

To quantify the relative increase in violent death rates in the growing region, we estimated growing-region/year interaction terms using the following equation:

$$
\ln \left(\mathrm{v}_{\mathrm{ajt}} / \mathrm{p}_{\mathrm{ajt}}\right)=\mu_{\mathrm{a}}+\beta_{\mathrm{j}}+\delta_{\mathrm{t}}+\Sigma_{\mathrm{s}} \alpha_{0 \mathrm{~s}} \mathrm{~g}_{\mathrm{js}}+\Sigma_{\mathrm{s}} \alpha_{1 \mathrm{~s}} \mathrm{~d}_{\mathrm{js}}+\varepsilon_{\mathrm{ajt}} .
$$

The dependent variable, $\ln \left(\mathrm{v}_{\mathrm{ajt}} / \mathrm{p}_{\mathrm{ajt}}\right)$, is the $\log$ death rate in cells defined by 10 -year age groups (indexed by a), department (indexed by $\mathrm{j}$ ), and year (indexed by $\mathrm{t}$ ). The term $\mu_{\mathrm{a}}$ is an age effect, while other parameters are defined as in equation (1). Also, as with the analysis in the previous section, some models include trends for each department type. ${ }^{21}$

Unweighted estimates of $\alpha_{0 \mathrm{~s}}$ and $\alpha_{1 \mathrm{~s}}$ are reported in Panel A of Table 7, while populationweighted estimates are shown in Panel B. Given the complete representation of departments in

\footnotetext{
${ }^{21}$ For purposes of estimation, the sample was expanded slightly to include ages 15-64 to accommodate the 10-year age groups. Data are analyzed for age-specific cells to control for changes in the age distribution due to migration and because mortality trends tend to be age-specific. Standard errors were adjusted for department/year clustering, though as far asymptotic inference based on cell size goes, these are population regression coefficients.
} 
population vital statistics, we report equally extensive sets of results with and without medium producers, but omit the analysis with pooled interactions. The unweighted estimates of $\alpha_{0 \mathrm{~s}}$ in Column (1) show an insignificant 12.3 percent increase in mortality in 1994 in the non-DMZ growing region, with no effect in 1993 (a specification check). The unweighted growing-region effect increases and is significantly different from zero by 1997, while the DMZ effect is significant from 1996-1999. Weighting tends to increase precision, so that the weighted estimate of the growing-region effect is significant in 1995. Omission of medium producers leads to larger and more significant effects. These results are reported in Columns (5)-(8); for example, Column (5) shows significant 1995 growing region effects around 0.2 in both weighted and unweighted specifications. ${ }^{22}$

Inclusion of region-specific trends leads to less precise estimates, though the weighted estimates are markedly larger when estimated with trends than without. None of the estimates using the 14department classification are significant when estimated with trends. On the other hand, weighted models with trends generate significant effects as early as 1994 when estimated without medium producers. These estimates are reported in Column (7).

The link between coca production and increased death rates may arise through a number of channels, some related to the fact that coca production is an illegal industry. In particular, those involved in the production of coca require private protection, sometimes involving violence and intimidation. Moreover, as we noted at the outset, coca is widely believed to provide sources of revenue for guerilla and paramilitary groups in rural areas, either through taxation, protection rackets, or direct control of production. In contrast, most of the violence associated with the cocaine trade occurred in large cities (most dramatically, in Medellin). Violence that arises through increased insurgent activity should therefore be a bigger problem in the countryside than in cities. To substantiate this, we estimated growing region effects on violent death rates separately for urban and rural victims. ${ }^{23}$

\footnotetext{
${ }^{22} \mathrm{DMZ}$ effects are (by construction) identical with and without medium producers since the medium producers are a subset of the non-DMZ growing region.

${ }^{23}$ DANE mortality files identify the type of area in which the deceased lived and the location of death. We defined urban/rural status by type of residence since hospitals where victims may die are mostly found in cities. For the purposes of our analysis, the deceased was identified as urban when residence was coded as "cabecera municipal."
} 
For the most part, estimates by urban/rural status indeed point to a stronger link between coca penetration and violent death rates in rural than urban areas. This is documented in Table 8, which reports estimates of equation (3) for rural residents in Panel A and for urban residents in Panel B. ${ }^{24}$ For example, the rural estimates of $\alpha_{0 \text { s }}$ in Column (1) are 0.31 (s.e. $=0.17$ ) for $1995,0.36$ (s.e. $=0.16$ ) for 1996, and 0.4 (s.e. $=0.17$ ) for 1997. The corresponding estimates for urban deaths, reported in Column (5), are $0.05,0.17$, and 0.11 (s.e. $=0.11$ ), none of which are significant. Overall, the contrast between Columns (1)-(2) in Panels A and B shows much larger effects in rural than urban areas. This pattern also persists in models that include trends (results reported in Columns (3) and (4)), with some of the effects on rural areas very large and significant (and the corresponding trends large and negative).

The contrast in results by urban/rural status using a sample that omits medium producers, reported in Columns (5)-(8) of Table 8, is less clear-cut than the contrast arising from estimates constructed using all 14 growing departments. On one hand, some of the estimates of $\alpha_{0 \text { s }}$ without regionspecific trends are slightly larger in urban than rural areas. On the other, until 1999, after the DMZ was ceded, the DMZ interaction terms are larger and more likely to be significant in rural than in urban areas. Moreover, estimates of models with trends also show much larger effects in rural than in urban areas (see Columns (7) and (8)). Again, all urban-area effects estimated in models with trends are insignificant. On balance, therefore, we see Table 8 as generally supporting the notion of larger growing-region effects on rural than urban violence.

\section{Summary and Conclusions}

The disruption of the Andean air bridge provides a unique opportunity to assess the impact of increased coca production on Colombia's rural population and to draw some wider lessons on the link between economic conditions and violence. On the economic side, we find evidence of an increase in

The urban residence variable is available only from 1992.

${ }^{24}$ The urban/rural distinction is used for the numerator but ignored in the population denominator. Since the model is in logs, this probably provides a reasonable approximation to an analysis of true death rates by urban/rural status. Estimates in Table 8 are unweighted since we do not have departmental population estimates by urban/rural status for intercensal years. 
self-employment income, though not in the likelihood of having income from this source, in the probability of working more generally, or in wage and salary earnings. The increase in self-employment income is estimated to be on the order of 13-29 log points, a fairly substantial gain. There is also some evidence for an effect on boys' labor supply. Because the gains appear to be fairly concentrated, it seems unlikely that increased coca production raised overall standards of living in growing areas. The absence of wider gains may be due to the fact that coca has few links with other sectors or to extortion on the part of insurgents and paramilitary forces and the fact that coca finances a conflict that reduces economic activity outside of the coca sector. ${ }^{25}$ Consistent with this latter view, our results show sharply increased violent death rates in growing areas.

Although we cannot conclusively identify specific channels through which coca abets violence, differences in effects by urban/rural status are also consistent with the notion that coca supports rural insurgents and paramilitary forces, thereby sustaining Colombia's civil conflict. Violence may also be used to enforce contracts in this illegal industry, though here the case for an urban/rural differential is less clear-cut. Remarkably, the increase in rural violence occurred against a backdrop of generally improving public health as measured by death rates from disease.

Our results provide an interesting case study of a situation where increases in income did not lead to a reduction in civil conflict, but rather fueled the fires of unrest. This contrasts with the more optimistic picture in Miguel, Satyanath, and Sergenti (2004), but is in line with journalistic accounts of the role played by blood diamonds in Africa's civil wars and economic theories of insurrection as extraction or extortion (e.g., Collier and Hoeffler, 2001; Grossman, 1991). Coca may indeed be emblematic of a new resource curse. Finally, we note that the disruption of the Andean air bridge was not the end of the aerial drug war. A recent account describes significant successes in the ongoing effort by US and Colombian forces to eradicate Colombia's coca crops by aerial spraying, and the continued suppression of coca production in Peru (Marquis and Forero, 2004). At the same time, Bolivian production is estimated to have increased 17 percent.

\footnotetext{
${ }^{25}$ Pshisva and Suarez (2004) suggest that the risk of kidnapping reduces investment by Colombian firms.
} 


\section{APPENDIX}

\section{$\underline{\text { Colombian Rural Household Surveys }}$}

The analysis here uses the "Encuesta Rural de Hogares", the rural component of the "Encuesta Nacional de Hogares," which became "Encuesta Continua de Hogares" (a panel) in 2001. The rural household survey was first conducted as a pilot in 1988. The survey was conducted again in December 1991 after the sampling methodology was updated and then on a consistent basis every September starting in 1992 until 2000. The survey collects data on a representative sample from 23 departments in four rural regions: Atlantic Region (which includes the departments Atlantico, Cordoba, Magdalena, Sucre, Cesar, La Guajira, and Bolivar); Pacific Region (which includes the departments of Choco, Nariño, Cauca, and Valle del Cauca); the Central Region (which includes the departments of Antioquia, Caldas, Huila, Tolima, Quindío, Risaralda, and Caqueta); and the Eastern Region (which includes the departments of Norte de Santander, Santander, Boyaca, Cundinamarca, and Meta).

\section{Rural definition}

The survey uses the following criteria to identify the rural population. The rural population includes:

1. The population of the city where the county's government is located if the city has less than 10,000 inhabitants.

2. The population of the city where the county's government is located if the city has more than 10,000 inhabitants and it meets one of the following characteristics:

(a) the percentage of residents in the city does not exceed $50 \%$ of the population in the entire county,

(b) the percentage of the active population engaged in agricultural activities exceeds $50 \%$, or

(c) the percentage of housing units without basic services (water, electricity, etc.) exceeds $20 \%$.

3. All population living in towns with less than 10,000 inhabitants.

4. All population not living either in cities or towns.

\section{Sampling methodology}

The sample for the survey is taken from the universe of the Census population living in private households. The sampling methodology consists of first generating strata according to geographical location and socioeconomic level; then, randomly drawing 'municipios' (the equivalent of counties in the U.S.) from these strata; next, randomly drawing neighborhoods from these 'municipios'; and, finally, randomly drawing blocks and then households from these neighborhoods. To facilitate the collection of information, households are grouped into 'segments' of 10 households on average. The typical year includes approximately 8,500 households, but the sample has increased over time. In particular, the sample size increased in 1996. The survey collected data from 148 municipios in 1992-1995, but it collected data from 197 municipios in 1996-2000.

In addition, the survey methodology changed as follows in 1996. First, between 1992 and 1995 the sample was drawn from the 1985 Census, while starting in 1996 and until 2000 the sample was drawn from the 1993 Census. Second, starting in 1996, interviewers were required to revisit households, which generated an increase in response rates. 


\section{Sample weights}

The survey weights include factors of adjustment to account for changes in subsampling and for nonresponse. So, we use the weighted data in our analysis to take account of the 1996 changes. In particular, the weights are estimated as:

$$
\mathrm{W}=(1 / \mathrm{P}) \times \mathrm{S} \times\left(\mathrm{I}_{\mathrm{S}} / \mathrm{N}_{\mathrm{S}}\right)
$$

where $\mathrm{P}$ is the probability of an individual being sampled and $\mathrm{S}$ is a weight given to segments. $\mathrm{S}$ equals 1 unless the number of households within the segment exceeds 10. The last term is the ratio of the number of households actually interviewed within a segment, $\mathrm{I}_{\mathrm{S}}$, and the number of households selected for interviewing within a segment, $\mathrm{N}_{\mathrm{S}}$, so it captures the response rate within a segment.

Since the average number of children per household is around 3, we generate within household averages for the children's data in order to avoid multiple observations per household. Likewise, since the weights are individual weights, we construct household weights by summing up the individual weights for all children within the household.

\section{Top-coding and imputation}

Labor market information is collected from individuals aged 10 and up. We impute zeros for the employment and hours of 8 and 9 year olds in the descriptive statistics in Table 5. Hours are collected from all employed workers, including salaried and wage workers as well as self-employed workers. Wage and salary earnings were collected for all jobs in 1992-1999. In 2000, wage and salary earnings were collected separately for the main job and for secondary jobs, so we exclude 2000 from the wage and salary regressions. Yearly self-employment income is collected separately as earnings from business and commercial activities and family-based agricultural production. In the original data, earnings and selfemployed income were top coded only between 1992 and 1995 . We impose uniform top-coding by applying a cap at the $95^{\text {th }}$ percentile (including zeros) for each year. In addition, we imputed the mean earnings and self-employment income by department and year for all those individuals who reported having earnings or self-employed income but did not report an amount.

\section{Colombian Urban Household Surveys}

We also use the urban component of the "Encuesta Nacional de Hogares," from 1992-2000. Coverage for the urban component of the survey is more limited than for the rural survey. In particular, the urban survey excluded the departments of Magdalena, Caqueta and Choco in 1992-1995. For the urban/rural analysis we used the 20 departments which are covered in both surveys in 1992-2000. Also, because Caqueta, one of the two DMZ departments, is not in the urban survey during the initial years, the urban/rural analysis omits Meta, the other DMZ department, and relies on specifications with non-DMZ growing interaction terms only.

The sampling methodology and sample weights used in the urban component are similar to those used in the rural component. The urban population includes all people not included under the rural definition.

As in the rural component of the survey, wage and salary earnings were collected for all jobs in 19921999, but in 2000 wage and salary earnings were collected separately for the main job and for secondary 
jobs, so the 2000 data are excluded from the wage and salary regressions. Yearly self-employment income is collected separately as earnings from business and commercial activities and the sale of domestically produced goods. In the urban component of the survey, earnings and self-employed income were top coded only between 1992 and 1996, so we apply the same uniform top-coding as used in the rural survey by applying a cap at the $95^{\text {th }}$ percentile (including zeros) for each year. We also imputed mean earnings and self-employment income by department and year for all those individuals who reported having earnings or self-employed income but did not report an amount.

\section{Mortality Detail Files}

We obtained mortality detail files from the Colombian national statistical agency, DANE, for 1990-2001. These files, the source of published vital statistics (e.g., http://www.dane.gov.co/inf_est/vitales.htm), show individual death records, with basic demographic information on the deceased and cause of death. The 1990 and 1991 files did not include reliable urban/rural codes and are therefore omitted from the sample used to construct Table 8 . The 2001 also had some inconsistencies (the file was provisional) and was therefore dropped.

\section{Cause of death}

We aggregate detailed causes of death on a consistent basis from year to year into the following larger groups: Homicide and suicide, accident and other non-violent trauma, disease, other causes, and other violent deaths. The violent death rate used here is the sum of Homicide and suicide plus other violent deaths. Data after 1997 show separate categories for general external causes not identified as accidents, and deaths due to actions by state and guerilla forces. These two categories appear to correspond to the "other violence category" from previous years.

\section{Location information}

Our construction of death rates by department and year is for department of death and not residence. Urban/rural status, however is by area of residence. This is coded somewhat differently from year to year. We established a consistent urban/rural by coding as urban those listed as living in "cabecera municipal" and coding the institutionalized as non-urban. Those with missing urban/rural status (about $1 / 16$ of deaths) are omitted from the analysis used to produce Table 8.

\section{Match to population information}

As noted in the text, population statistics for each department-year-age(5 year)-sex category were obtained from DANE (1998) for 1990, 1995, and 2000. The Colombian census used for these data was conducted in 1993, so data for other years are inter-censal estimates and projections. We interpolated using 5-year growths for each cell.

Finally, we aggregated mortality counts to match 5-year age bands, and then matched to the relevant population denominators. 


\section{REFERENCES}

Abadie, Alberto (2004), "Poverty, Political Freedom, and the Roots of Terrorism," NBER Working Paper 10859, October.

Alvarez, Elena H. (1995), "Economic Development, Restructuring and the Illicit Drug Sector in Bolivia and Peru: Current Policies," Journal of Interamerican Studies and World Affairs 37 (3), 125-49,

Angrist, Joshua (2001), "Estimate of Limited-Dependent Variable Models with Dummy Endogenous Regressors: Simple Strategies for Empirical Practice," Journal of Business and Economic Statistics 19(1), 2-16.

Bagley, Bruce M. (1989), “Colombia and the War on Drugs,” Foreign Affairs 67 (Fall 1998), 70-92.

Black, Dan, Terra McKinnish, and Seth Sanders (2005), "The Economic Impact of the Coal Boom and Bust," Economic Journal, April.

Black, Dan, Kermit Daniel, and Seth Sanders (2002), “The Impact of Economic Conditions on Disability Program Participation: Evidence from the Coal Boom and Bust," American Economic Review 92 (March), 27-50.

Cardenas, Mauricio (2001), "Economic Growth in Colombia: A Reversal of Fortune?," Harvard Center for International development Working Paper 83, December.

Carrington, William J (1996), “The Alaskan Labor Market During the Pipeline Era," Journal of Political Economy 104 (February), 186-218.

Chauvin, Lucien (1999), "Drug Eradication Effort Worsens Poverty Among Bolivian Farmers," The Miami Herald, 25 January.

CODHES, Consultoria para los Derechos Humanos y el Desplazamiento (1996), Desplazamiento Rural: Violencia y Pobres, <http://www.codhes.org.co/>.

Collier, Paul and Anke Hoeffler (2004), "Greed and Grievance in Civil War," Oxford Economic Papers 56, 563-595.

Collier, Paul, Anke Hoeffler, and Mans Soderbom (2004), "On the Duration of Civil War," Journal of Peace Research 41, 253-273

Departmento Administrativo Nacional de Estadistica (1998), Colombia: Proyecciones Departamentales de Poblacion por Sexo y Edad, 1990-2015, (in Serial Estudios Censales), Bogota, D.C.: DANE.

Departmento Administrativo Nacional de Estadistica (1999), Guia Metodología: Encuesta Nacional de Hogares, Bogota, D.C.: DANE, Direccion Tecnica de Estadisticas Basicas.

Departmento Administrativo Nacional de Estadistica (2002), Metodología Encuesta Continua de Hogares, Bogota, D.C.: DANE, Direccion de Metodologia y Produccion Estadistica. 
Diaz, Ana Maria and Fabio Sanchez (2004), "Geography if Illicit Crops (Coca Leaf) and Armed Conflict in Colombia," The Development Research Centre, Development Studies Institute, London School of Economics, February.

Edmunds, Eric V., and Nina Pavenik (2004), "International Trade and Child Labor: Cross-Country Evidence," NBER Working Paper 10317, February.

Fearon, James D. and David D. Laitin (2003), "Ethnicity, Insurgency, and Civil War," American Political Science Review 97 (February), 75-90.

Gaviria, Alejandro (2000), "Increasing Returns and the Evolution of Violent Crime: The Case of Colombia," Journal of Development Economics 61(1), 1-25.

Government of Colombia, Dirección Nacional de Estupefacientes (DNE, 2002), "Cultivos Ilícitos y el Programa de Erradicación,” Bogotá: 2002, <http//www.dnecolombia.gov.co/contenido.php?sid=18>.

Grossman, Herschel I. (1991), "A General Equilibrium Model of Insurrection," American Economic Review 81, 912-921.

Grossman, Herschel I. and Daniel Mejia (2005), "The War Against Drug Producers," NBER Working Paper 11141, February.

Fearon, James D. (2004), 'Why Do Some Civil Wars Last So Much Longer than Others?,' Journal of Peace Research 41, 275-301.

Federal Research Division (1988), Colombia, in Dennis M. Hanratty and Sandra W. Meditz, eds, Country Studies/Area Handbook Series, Washington, DC: The Library of Congress (material on the FARC available at http://www.country-data.com/cgi-bin/query/r-3126.html).

Hausmann, Ricardo, and Roberto Rigobon (2003), “An Alternative Interpretation of the 'Resource Curse': Theory and Policy Implications,” NBER Working Paper 9424, January.

Kirk, Robin (2003), More Terrible than Death: Massacres, Drugs, and America's War in Colombia," New York: Public Affairs.

Krueger, Alan and Jitka Maleckova (2002), "Education, Poverty, Political Violence and Terrorism: Is There a Causal Connection?,” NBER Working Paper No. 9072.

Krueger, Alan and D.D. Laitin (2003), "Kto Kogo? A Cross-Country Study of the Origins and Targets of Terrorism," Princeton University Department of Economics, mimeo, November.

Leons, Madeline B. (1997), "After the Boom: Income Decline, Eradication, and Alternative Development in the Yungas," Chapter 6 in M.B. leons and H. Sanabria, eds., Coca, Cocaine, and the Bolivian Reality, Albany; State University of New York Press.

Marquis, Christopher and Juan Forero (2004), "U.S. Announces Gains in Eradicating Andean Coca," The New York Times, March 23. 
Miguel, Edward, S. Satyanath, and E. Sergenti (2004), "Economic Shocks and Civil Conflict: An Instrumental Variables Approach,” Journal of Political Economy 112(4), 725-753.

Ministerio de Defensa Nacional (2001), "Homicidio y Control de Armas en Colombia," Bogota, July (available as http://www.mindefensa.gov.co/publicaciones/ministerio/espanol/armas-documento.pdf).

Perafan, Carlos Cesar (1999), "Impacto de Cultivos Ilicitos en Pueblos Indigenas: El Caso de Colombia," No. IND-106, Bogota: Proyecto de Desarrollo Alternativo (PLANTE).

Pshisva, Rony and Gustavo A. Suarez (2004), "Crime and Finance: Evidence from Colombia," Harvard University Department of Economics, mimeo, November.

Rabasa, Angel, and Peter Chalk (2001), Colombian Labyrinth: The Synergy of Drugs and Insurgency and Its Implications for Regional Stability, Los Angeles: The RAND Corporation.

Rangel, Alfredo (2000), "Parasites and predators: Guerillas and the Insurrection economy of Colombia, Journal of International Affairs (Spring 2000), 577-601.

Ross, Michael (2003), “How Do Natural Resources Influence Civil War?,” International Organization 58 Winter.

Ross, Michael (2004), "What Do we Know About Natural Resources and Civil War?, Journal of Peace Research 41, 337-356.

Sala-i-Martin, Xavier and Arvind Subramanian (2003), 'Addressing the Resource Curse: An Illustration from Nigeria," NBER Working Paper 9804, June.

Sachs, J. and A.M. Warner (2000), "Natural Resource Abundance and Economic Growth," in G.M. Meier and J.E. Rauch (eds), Leading Issues in Economic Development, $7^{\text {th }}$ ed., Oxford: Oxford University Press.

Sanchez Torres, F., and J. Nunez Mendez (2000), "Geography and Economic Development in Colombia: A Municipal Approach,” Latin American research network Working Paper R-408, The IADB.

Steiner, Roberto (1998), "Colombia's Income from the Drug Trade," World Development 26(6), 10131031.

Thoumi, Francisco E. (1995), Political Economy and Illegal Drugs in Colombia, Boulder: Lynne Rienner Publishers.

Thoumi, Francisco E. (2002), "Illegal drugs in Colombia: From Illegal Economic Boom to Social crisis," Annals of the American Academy of Political and Social Science 582 (July), 102-116.

United Nations (2001), Global Illicit Drug Trends 2001, New York; United Nations Office for Drug Control and Crime Prevention.

United Nations (2002), Colombia: Internally Displaced Persons, Geneva: United Nations High Commissioner for Refugees (maps available in http://www.unhcr.ch//). 
United Nations (2003), Colombia: Coca Survey for 2002, New York: United Nations Office for Drug Control and Crime Prevention.

Urdinola, Piedad (2004), “The Hidden Cost of Violence, Infant Mortality in Colombia," paper presented at the First Congress of the Latin American Population Association, Brazil.

Uribe, Sergio (1997), "Los Cultivos Ilicitos en Colombia," Chapter 1 in F.E. Thoumi, et al., eds., Drogas Ilicitas en Colombia: Su Impacto Economico, Politico y Social, Bogota: Ministerio de Justicia y del Derecho, Direccion Nacional de Estupefacientes.

Villalon, Carlos (2004), “Cocaine Country,” National Geographic, July.

Washington Office on Latin America (1991), Clear and Present Dangers: The U.S. Military and the War on Drugs in the Andes," WOLA: Washington, DC.

Whynes, David K. (1992), 'The Colombian Cocaine Trade and the War on Drugs," Chapter 12 in A. Cohen and R.Segovia, eds., The Colombian Economy: Issues of Trade and Development," Boulder: Westview Press.

Winn, Peter (1999), Americas: The Changing Face of Latin America and the Caribbean," Berkeley and Los Angeles: University of California Press.

Zirnite, Peter (1998), "The Militarization of the Drug War in Latin America," Current History 97, 618 (April), 166-173. 


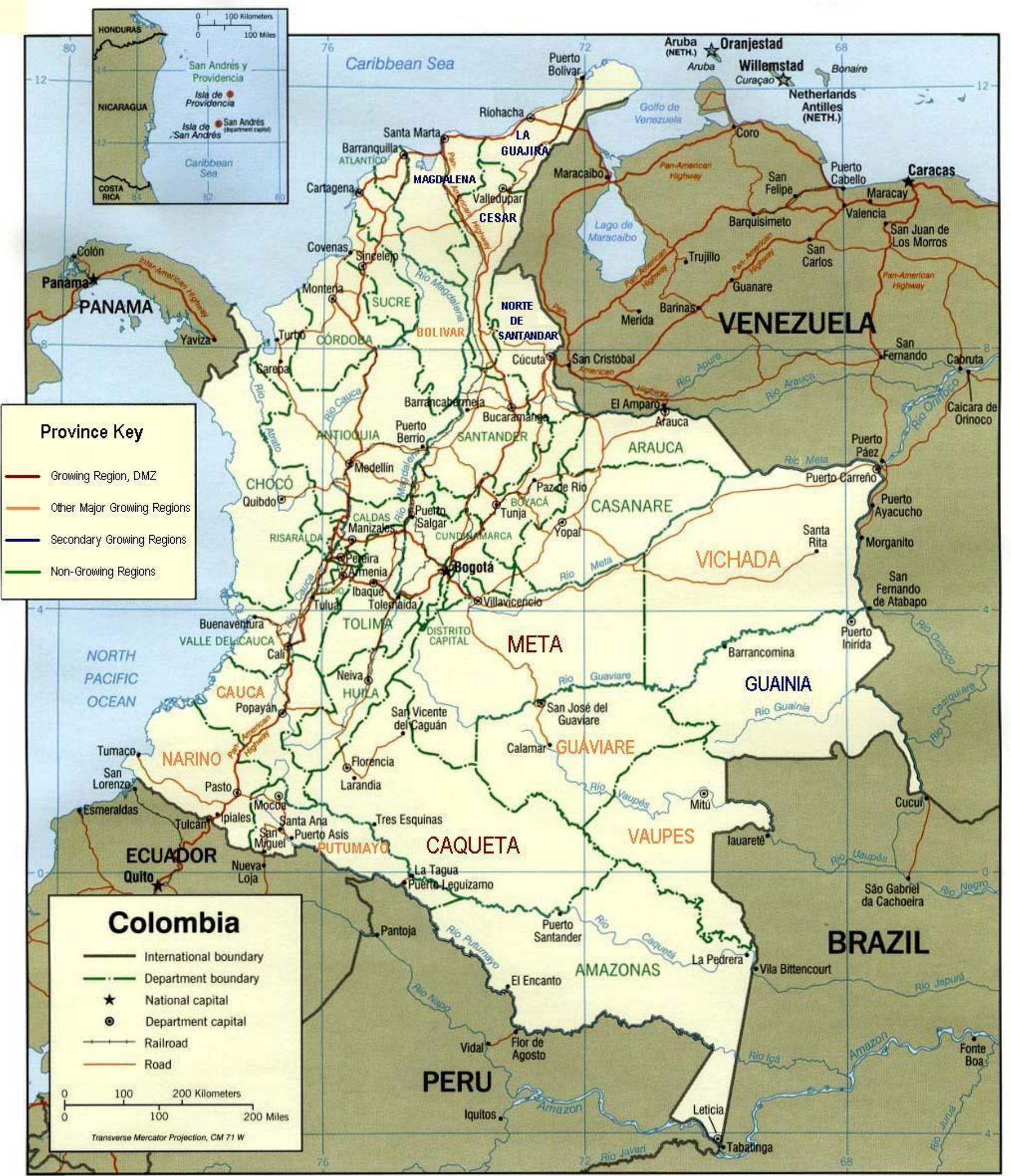

Base 802670Al (R00820) 6-01 
TABLE 1. FIRST STAGE FOR COCA CULTIVATION GROWTH

\begin{tabular}{|c|c|c|c|c|c|c|c|c|c|}
\hline \multirow[b]{2}{*}{ Treatment group } & \multirow[b]{2}{*}{ Parameter } & \multicolumn{4}{|c|}{1994 to 1999} & \multicolumn{4}{|c|}{1994 to 2000} \\
\hline & & (1) & (2) & (3) & (4) & (5) & (6) & (7) & (8) \\
\hline
\end{tabular}

A. With DMZ departments

\begin{tabular}{cccccc}
9 growing dept. & Intercept & 735 & 207 & 506 & 292 \\
& & $(1,749)$ & $(2,112)$ & $(2,024)$ & $(2,458)$ \\
& \multirow{2}{*}{ Growing } & 7,554 & 8,082 & 8,748 & 8,961 \\
& & $(3,445)$ & $(3,724)$ & $(3,876)$ & $(4,358)$
\end{tabular}

14 growing dept. Intercept

207

$(2,053)$

292

$(2,348)$

6,100

6,127

Growing

$(3,152)$

$(3,604)$

Linear Intercept

1,658

2,147

(1,708)

(1,989)

Hectares

.553

(.321)

(.373)

Includes medium

control no treated yes

producers?

$R^{2}$

0.134

0.121

$0.108 \quad 0.087$

0.141

0.107

0.085

0.029

B. Without DMZ departments

9 growing dept. Intercept $735 \quad 207$

$\begin{array}{cc}506 & 292 \\ (2074) & (4,911) \\ 9,533 & 9,746 \\ (4,364) & (4,911)\end{array}$

14 growing dept. Intercept

207

292

$(2,115)$

$(2,414)$

6,287

6,112

$(3,400)$

$(3,879)$

Linear

Intercept

1,699

2,201

(1,759)

$(2,057)$

.697

.328

(.398)

(.466)

Includes medium

control no treated yes

control

no

treated

yes

producers?

$R^{2}$

$0.140 \quad 0.125$

$0.106 \quad 0.091$

0.141

0.105

$0.079 \quad 0.017$

Notes: The table reports estimates of the change in cocaine cultivation on 1994 levels for the 33 Colombia Departments (states). The 1994 variable is the average of 4 measures from Thoumi et al. (1997). The 1999 and 2000 data are police estimates, reported in Government of Colombia (2002). 


\begin{tabular}{|c|c|c|c|c|c|c|}
\hline \multirow[b]{2}{*}{ Region type } & \multirow[b]{2}{*}{ Department } & \multirow{2}{*}{$\begin{array}{c}\text { Population } \\
1993 \\
(1) \\
\end{array}$} & \multirow{2}{*}{$\begin{array}{c}\text { \% Urban } \\
1993 \\
\text { (2) }\end{array}$} & \multicolumn{2}{|c|}{ Enrollment } & \multirow{2}{*}{$\begin{array}{c}\text { Homicide Rate } \\
\text { 1990-1993 } \\
\text { (5) }\end{array}$} \\
\hline & & & & $\begin{array}{c}\text { \% Primary } \\
1995 \\
(3) \\
\end{array}$ & $\begin{array}{c}\text { \% Secondary } \\
1995 \\
\text { (4) }\end{array}$ & \\
\hline \multirow[t]{16}{*}{ Non-growing } & Santafe de Bogota, DC & $4,945,448$ & 99.7 & 60.8 & 75.2 & 178.8 \\
\hline & Amazonas & 37,764 & 50.4 & 56.3 & 33.2 & 35.3 \\
\hline & Arauca & 137,193 & 63.6 & 90.0 & 38.8 & 226.3 \\
\hline & Atlantico & $1,667,500$ & 93.7 & 68.2 & 67.9 & 65.2 \\
\hline & Boyaca & $1,174,031$ & 42.5 & 65.8 & 47.4 & 124.1 \\
\hline & Caldas & 925,358 & 64.7 & 66.2 & 56.3 & 251.6 \\
\hline & Casanare & 158,149 & 54.7 & 77.9 & 34.5 & 153.1 \\
\hline & Huila & 758,013 & 60.0 & 73.9 & 47.7 & 132.6 \\
\hline & Quindio & 435,018 & 83.8 & 64.7 & 65.0 & 173.0 \\
\hline & Risaralda & 744,974 & 81.3 & 66.1 & 59.1 & 303.4 \\
\hline & San Andres y Providencia & 50,094 & 70.4 & 69.7 & 84.2 & 44.1 \\
\hline & Santander & $1,598,688$ & 68.9 & 68.9 & 53.3 & 192.7 \\
\hline & Sucre & 624,463 & 67.1 & 96.6 & 51.3 & 38.5 \\
\hline & Tolima & $1,150,080$ & 60.7 & 71.9 & 55.5 & 140.9 \\
\hline & Valle del Cauca & $3,333,150$ & 85.3 & 71.9 & 62.6 & 311.5 \\
\hline & All 19 non-growing & $25,167,215$ & 75.5 & 70.9 & 59.8 & 271.6 \\
\hline \multirow{5}{*}{ growing } & Narino & $1,274,708$ & 42.9 & 62.4 & 33.7 & 58.7 \\
\hline & Putumayo & 204,309 & 34.6 & 75.4 & 28.0 & 170.7 \\
\hline & Vaupes & 18,235 & 24.8 & 74.9 & 21.4 & 2.8 \\
\hline & Vichada & 36,336 & 24.1 & 54.2 & 16.6 & 39.3 \\
\hline & All 9-dept w/o DMZ & $4,009,994$ & 49.8 & 70.6 & 39.4 & 86.5 \\
\hline \multirow[t]{3}{*}{ 9-Dept, DMZ } & Caqueta & 311,464 & 46.0 & 76.4 & 31.7 & 205.2 \\
\hline & Meta & 561,121 & 64.0 & 72.9 & 52.2 & 204.7 \\
\hline & All DMZ & 872,585 & 57.5 & 74.3 & 44.3 & 204.9 \\
\hline \multirow{7}{*}{$\begin{array}{l}\text { Medium } \\
\text { producers }\end{array}$} & Cesar & 729,634 & 62.9 & 82.1 & 50.7 & 146.2 \\
\hline & Guainia & 13,491 & 30.4 & 43.3 & 17.1 & 45.3 \\
\hline & La Guajira & 387,773 & 64.3 & 72.5 & 58.5 & 135.8 \\
\hline & Magdalena & 882,571 & 64.0 & 67.7 & 41.0 & 70.8 \\
\hline & Norte de Santander & $1,046,577$ & 70.8 & 67.8 & 42.4 & 241.2 \\
\hline & All medium producers & $3,060,046$ & 66.0 & 71.7 & 45.6 & 150.6 \\
\hline & All Departments & $33,109,840$ & 71.0 & 71.1 & 55.2 & 235.8 \\
\hline
\end{tabular}

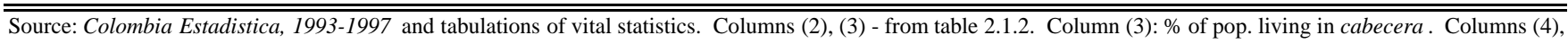
(5) - from tables 10.2.1 and 10.3.1. Column (4): primary enrollment divided by pop. aged 5-9 plus 60\% of the pop. aged 10-14. Column (5): secondary enrollment divided by $40 \%$ of the pop. aged 10-14 plus pop. aged 15-19. Homicide rates are for men aged 15-59, per 100,000. 
TABLE 3. DESCRIPTIVE STATISTICS FOR RURAL SURVEY

\begin{tabular}{|c|c|c|c|c|c|c|c|c|c|c|}
\hline \multirow[b]{2}{*}{ Variable } & \multicolumn{2}{|c|}{$\begin{array}{c}\text { Adult workers } \\
\text { (men and women) }\end{array}$} & \multicolumn{2}{|c|}{$\begin{array}{l}\text { Adult Workers } \\
\text { (men) }\end{array}$} & \multicolumn{2}{|c|}{ Boys } & \multicolumn{2}{|c|}{ Girls } & \multicolumn{2}{|c|}{$\begin{array}{c}\text { Teenage Workers } \\
\text { (boys) }\end{array}$} \\
\hline & $\begin{array}{c}1992 \\
(1) \\
\end{array}$ & $\begin{array}{c}1997 \\
(2) \\
\end{array}$ & $\begin{array}{c}1992 \\
(3) \\
\end{array}$ & $\begin{array}{c}1997 \\
(4) \\
\end{array}$ & $\begin{array}{c}1992 \\
(5) \\
\end{array}$ & $\begin{array}{c}1997 \\
(6) \\
\end{array}$ & $\begin{array}{c}1992 \\
(7) \\
\end{array}$ & $\begin{array}{c}1997 \\
(8) \\
\end{array}$ & $\begin{array}{c}1992 \\
(9) \\
\end{array}$ & $\begin{array}{l}1997 \\
(10) \\
\end{array}$ \\
\hline Employed & $\begin{array}{c}0.658 \\
(0.474)\end{array}$ & $\begin{array}{c}0.647 \\
(0.478)\end{array}$ & $\begin{array}{l}0.950 \\
(0.219)\end{array}$ & $\begin{array}{l}0.931 \\
(0.253)\end{array}$ & $\begin{array}{l}0.360 \\
(0.436)\end{array}$ & $\begin{array}{l}0.283 \\
(0.413)\end{array}$ & $\begin{array}{l}0.095 \\
(0.264)\end{array}$ & $\begin{array}{l}0.077 \\
(0.250)\end{array}$ & $\begin{array}{l}0.600 \\
(0.450)\end{array}$ & $\begin{array}{l}0.506 \\
(0.458)\end{array}$ \\
\hline Hours Worked per month & $\begin{array}{c}142.3 \\
(117.3)\end{array}$ & $\begin{array}{c}131.8 \\
(115.0)\end{array}$ & $\begin{array}{l}219.3 \\
(76.8)\end{array}$ & $\begin{array}{l}200.3 \\
(85.2)\end{array}$ & $\begin{array}{c}65.6 \\
(86.9)\end{array}$ & $\begin{array}{c}44.9 \\
(74.3)\end{array}$ & $\begin{array}{l}15.4 \\
(47.8)\end{array}$ & $\begin{array}{c}11.2 \\
(39.7)\end{array}$ & $\begin{array}{c}121.2 \\
(103.0)\end{array}$ & $\begin{array}{c}94.1 \\
(96.6)\end{array}$ \\
\hline Monthly Wages & $\begin{array}{c}74,098 \\
(115,512)\end{array}$ & $\begin{array}{c}81,461 \\
(127,287)\end{array}$ & $\begin{array}{c}115,439 \\
(126,002)\end{array}$ & $\begin{array}{c}123,636 \\
(137,069)\end{array}$ & & & & & $\begin{array}{c}61,038 \\
(78,522)\end{array}$ & $\begin{array}{c}58,921 \\
(84,989)\end{array}$ \\
\hline Positive Wages & 0.362 & 0.369 & 0.551 & 0.555 & & & & & 0.418 & 0.350 \\
\hline SE Income (5\% top code) & $\begin{array}{c}337,712 \\
(815,718)\end{array}$ & $\begin{array}{c}352,969 \\
(865,459)\end{array}$ & $\begin{array}{c}557,381 \\
(1,026,941)\end{array}$ & $\begin{array}{c}551,260 \\
(1,048,327)\end{array}$ & & & & & $\begin{array}{c}61,196 \\
(311,898)\end{array}$ & $\begin{array}{c}65,253 \\
(291,899)\end{array}$ \\
\hline Positive SE Income & 0.247 & 0.259 & 0.348 & 0.371 & & & & & 0.066 & 0.080 \\
\hline Enrolled & 0.017 & 0.028 & 0.014 & 0.024 & 0.694 & 0.779 & 0.757 & 0.815 & 0.397 & 0.486 \\
\hline Age & $\begin{array}{l}36.43 \\
(10.65)\end{array}$ & $\begin{array}{l}37.02 \\
(10.62)\end{array}$ & $\begin{array}{l}36.60 \\
(10.68)\end{array}$ & $\begin{array}{c}37.12 \\
(10.63)\end{array}$ & $\begin{array}{l}11.91 \\
(2.10)\end{array}$ & $\begin{array}{l}11.94 \\
(2.18)\end{array}$ & $\begin{array}{l}11.87 \\
(2.15)\end{array}$ & $\begin{array}{l}11.90 \\
(2.19)\end{array}$ & $\begin{array}{l}16.16 \\
(1.95)\end{array}$ & $\begin{array}{l}16.22 \\
(1.90)\end{array}$ \\
\hline HH Size & $\begin{array}{l}5.60 \\
(2.56)\end{array}$ & $\begin{array}{l}5.32 \\
(2.49)\end{array}$ & $\begin{array}{l}5.56 \\
(2.60)\end{array}$ & $\begin{array}{l}5.31 \\
(2.51)\end{array}$ & $\begin{array}{l}6.60 \\
(2.36)\end{array}$ & $\begin{array}{l}6.35 \\
(2.41)\end{array}$ & $\begin{array}{l}6.66 \\
(2.36)\end{array}$ & $\begin{array}{l}6.41 \\
(2.43)\end{array}$ & $\begin{array}{l}6.57 \\
(2.48)\end{array}$ & $\begin{array}{l}6.35 \\
(2.57)\end{array}$ \\
\hline Migrant & 0.282 & 0.316 & 0.280 & 0.312 & 0.133 & 0.161 & 0.163 & 0.160 & 0.161 & 0.182 \\
\hline Single & 0.229 & 0.221 & 0.284 & 0.277 & 1.00 & 0.999 & 0.990 & 0.981 & 0.981 & 0.970 \\
\hline Male & 0.496 & 0.597 & & & & & & & & \\
\hline Growing (14-dept) & 0.235 & 0.303 & 0.234 & 0.309 & 0.262 & 0.332 & 0.250 & 0.336 & 0.238 & 0.332 \\
\hline Growing (9-depts) & 0.137 & 0.181 & 0.133 & 0.180 & 0.147 & 0.191 & 0.138 & 0.198 & 0.138 & 0.197 \\
\hline DMZ & 0.014 & 0.039 & 0.014 & 0.039 & 0.013 & 0.040 & 0.014 & 0.044 & 0.011 & 0.034 \\
\hline Max N & 13,550 & 19,184 & 6,641 & 9,801 & 2,602 & 3,513 & 2,477 & 3,253 & 2,040 & 2,881 \\
\hline
\end{tabular}

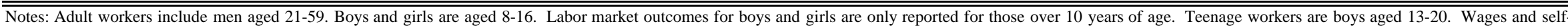
employment income include zeros and are in real (1998) pesos, about 1,400 to the US dollar. 
TABLE 4a. ADULT LABOR MARKET OUTCOMES - YEARLY INTERACTIONS, POOLED GROWING \& DMZ

\begin{tabular}{|c|c|c|c|c|c|c|c|c|c|c|}
\hline \multirow[b]{3}{*}{$\begin{array}{c}\text { Interaction } \\
\text { Terms }\end{array}$} & \multicolumn{4}{|c|}{ Male and Female Workers } & \multicolumn{6}{|c|}{ Men Only } \\
\hline & \multicolumn{2}{|c|}{ Positive SE Income } & \multicolumn{2}{|c|}{ Log SE Income } & \multicolumn{2}{|c|}{ Employed } & \multicolumn{2}{|c|}{ Log Hours (All Jobs) } & \multicolumn{2}{|c|}{$\begin{array}{l}\text { Log Monthly Wage and } \\
\text { Salary Earnings }\end{array}$} \\
\hline & $\begin{array}{l}\text { All } \\
(1)\end{array}$ & $\begin{array}{l}\text { w/o Migrants } \\
\text { (2) }\end{array}$ & $\begin{array}{l}\text { All } \\
\text { (3) }\end{array}$ & $\begin{array}{c}\text { w/o Migrants } \\
\text { (4) }\end{array}$ & $\begin{array}{l}\text { All } \\
(5)\end{array}$ & $\begin{array}{c}\text { w/o Migrants } \\
\text { (6) }\end{array}$ & $\begin{array}{l}\text { All } \\
\text { (7) }\end{array}$ & $\begin{array}{c}\text { w/o Migrants } \\
\text { (8) }\end{array}$ & $\begin{array}{l}\text { All } \\
(9)\end{array}$ & $\begin{array}{c}\text { w/o Migrants } \\
\text { (10) }\end{array}$ \\
\hline 1994 & $\begin{array}{c}-0.035 \\
(0.023)\end{array}$ & $\begin{array}{c}-0.046 \\
(0.024)\end{array}$ & $\begin{array}{l}-0.025 \\
(0.175)\end{array}$ & $\begin{array}{c}0.080 \\
(0.161)\end{array}$ & $\begin{array}{c}-0.014 \\
(0.013)\end{array}$ & $\begin{array}{c}-0.019 \\
(0.016)\end{array}$ & $\begin{array}{l}-0.026 \\
(0.023)\end{array}$ & $\begin{array}{c}-0.031 \\
(0.025)\end{array}$ & $\begin{array}{c}0.014 \\
(0.036)\end{array}$ & $\begin{array}{c}0.027 \\
(0.038)\end{array}$ \\
\hline 1995 & $\begin{array}{c}0.009 \\
(0.024)\end{array}$ & $\begin{array}{c}0.002 \\
(0.023)\end{array}$ & $\begin{array}{c}0.159 \\
(0.153)\end{array}$ & $\begin{array}{c}0.190 \\
(0.155)\end{array}$ & $\begin{array}{c}-0.002 \\
(0.012)\end{array}$ & $\begin{array}{c}-0.008 \\
(0.012)\end{array}$ & $\begin{array}{c}0.004 \\
(0.024)\end{array}$ & $\begin{array}{c}0.006 \\
(0.029)\end{array}$ & $\begin{array}{l}-0.011 \\
(0.037)\end{array}$ & $\begin{array}{l}-0.008 \\
(0.038)\end{array}$ \\
\hline 1996 & $\begin{array}{c}0.042 \\
(0.030)\end{array}$ & $\begin{array}{c}0.049 \\
(0.030)\end{array}$ & $\begin{array}{c}0.362 \\
(0.131)\end{array}$ & $\begin{array}{c}0.414 \\
(0.141)\end{array}$ & $\begin{array}{c}0.003 \\
(0.014)\end{array}$ & $\begin{array}{l}-0.010 \\
(0.015)\end{array}$ & $\begin{array}{c}0.034 \\
(0.028)\end{array}$ & $\begin{array}{c}0.048 \\
(0.033)\end{array}$ & $\begin{array}{c}-0.008 \\
(0.041)\end{array}$ & $\begin{array}{c}0.002 \\
(0.049)\end{array}$ \\
\hline 1997 & $\begin{array}{c}0.025 \\
(0.020)\end{array}$ & $\begin{array}{c}0.035 \\
(0.019)\end{array}$ & $\begin{array}{c}0.270 \\
(0.122)\end{array}$ & $\begin{array}{c}0.292 \\
(0.116)\end{array}$ & $\begin{array}{c}-0.005 \\
(0.014)\end{array}$ & $\begin{array}{c}-0.013 \\
(0.018)\end{array}$ & $\begin{array}{l}-0.001 \\
(0.030)\end{array}$ & $\begin{array}{c}0.002 \\
(0.036)\end{array}$ & $\begin{array}{c}0.010 \\
(0.041)\end{array}$ & $\begin{array}{c}0.028 \\
(0.046)\end{array}$ \\
\hline 1998 & $\begin{array}{c}-0.020 \\
(0.025)\end{array}$ & $\begin{array}{l}-0.009 \\
(0.023)\end{array}$ & $\begin{array}{c}0.302 \\
(0.162)\end{array}$ & $\begin{array}{c}0.291 \\
(0.183)\end{array}$ & $\begin{array}{c}0.0004 \\
(0.012)\end{array}$ & $\begin{array}{c}-0.012 \\
(0.014)\end{array}$ & $\begin{array}{c}0.053 \\
(0.020)\end{array}$ & $\begin{array}{c}0.035 \\
(0.021)\end{array}$ & $\begin{array}{c}0.103 \\
(0.056)\end{array}$ & $\begin{array}{c}0.107 \\
(0.058)\end{array}$ \\
\hline 1999 & $\begin{array}{c}0.007 \\
(0.022)\end{array}$ & $\begin{array}{c}0.016 \\
(0.021)\end{array}$ & $\begin{array}{c}0.205 \\
(0.133)\end{array}$ & $\begin{array}{c}0.150 \\
(0.136)\end{array}$ & $\begin{array}{c}0.015 \\
(0.010)\end{array}$ & $\begin{array}{c}0.007 \\
(0.012)\end{array}$ & $\begin{array}{c}0.006 \\
(0.021)\end{array}$ & $\begin{array}{c}0.005 \\
(0.023)\end{array}$ & $\begin{array}{c}0.069 \\
(0.038)\end{array}$ & $\begin{array}{c}0.067 \\
(0.039)\end{array}$ \\
\hline 2000 & $\begin{array}{c}0.044 \\
(0.023)\end{array}$ & $\begin{array}{c}0.052 \\
(0.022)\end{array}$ & $\begin{array}{c}0.255 \\
(0.145)\end{array}$ & $\begin{array}{c}0.230 \\
(0.155)\end{array}$ & $\begin{array}{l}-0.003 \\
(0.011)\end{array}$ & $\begin{array}{l}-0.012 \\
(0.013)\end{array}$ & $\begin{array}{c}0.065 \\
(0.020)\end{array}$ & $\begin{array}{c}0.085 \\
(0.022)\end{array}$ & & \\
\hline $\mathrm{N}$ & 147,833 & 100,284 & 40,338 & 28,912 & 74,781 & 50,914 & 69,144 & 46,770 & 34,451 & 22,257 \\
\hline
\end{tabular}

Notes: The table reports growing region/year interactions. Estimates for monthly wages omit data for 2000. Standard errors adjusted for department-year clustering are reported in parentheses. 
TABLE 4b. ADULT LABOR MARKET OUTCOMES WITH POOLED INTERACTION TERMS

\begin{tabular}{|c|c|c|c|c|c|c|c|c|c|c|}
\hline \multirow[b]{3}{*}{$\begin{array}{c}\text { Interaction } \\
\text { Terms } \\
\end{array}$} & \multicolumn{4}{|c|}{ Male and Female Workers } & \multicolumn{6}{|c|}{ Men Only } \\
\hline & \multicolumn{2}{|c|}{ Positive SE Income } & \multicolumn{2}{|c|}{ Log SE Income } & \multicolumn{2}{|c|}{ Employed } & \multicolumn{2}{|c|}{ Log Hours (All Jobs) } & \multicolumn{2}{|c|}{$\begin{array}{c}\text { Log Monthly Wage and } \\
\text { Salary Earnings }\end{array}$} \\
\hline & $\begin{array}{c}\text { No Trends } \\
(1) \\
\end{array}$ & $\begin{array}{c}\text { w/Trends } \\
(2) \\
\end{array}$ & $\begin{array}{c}\text { No Trends } \\
\text { (3) } \\
\end{array}$ & $\begin{array}{c}\text { w/Trends } \\
(4) \\
\end{array}$ & $\begin{array}{c}\text { No Trends } \\
(5)\end{array}$ & $\begin{array}{c}\text { w/Trends } \\
(6) \\
\end{array}$ & $\begin{array}{c}\text { No Trends } \\
(7) \\
\end{array}$ & $\begin{array}{c}\text { w/Trends } \\
\text { (8) } \\
\end{array}$ & $\begin{array}{l}\text { No Trends } \\
(9) \\
\end{array}$ & $\begin{array}{c}\text { w/Trends } \\
(10) \\
\end{array}$ \\
\hline \multicolumn{11}{|c|}{ Panel A: Growing Effects (non-DMZ) } \\
\hline 1995-1997 & $\begin{array}{c}0.039 \\
(0.017)\end{array}$ & $\begin{array}{c}0.006 \\
(0.031)\end{array}$ & $\begin{array}{c}0.251 \\
(0.100)\end{array}$ & $\begin{array}{c}0.288 \\
(0.196)\end{array}$ & $\begin{array}{l}0.0045 \\
(0.009)\end{array}$ & $\begin{array}{l}0.0079 \\
(0.015)\end{array}$ & $\begin{array}{c}0.020 \\
(0.019)\end{array}$ & $\begin{array}{c}0.013 \\
(0.028)\end{array}$ & $\begin{array}{l}-0.0051 \\
(0.028)\end{array}$ & $\begin{array}{l}-0.035 \\
(0.052)\end{array}$ \\
\hline $1998-2000$ & $\begin{array}{c}0.031 \\
(0.017)\end{array}$ & $\begin{array}{l}-0.036 \\
(0.049)\end{array}$ & $\begin{array}{c}0.260 \\
(0.106)\end{array}$ & $\begin{array}{c}0.333 \\
(0.340)\end{array}$ & $\begin{array}{c}0.013 \\
(0.008)\end{array}$ & $\begin{array}{c}0.020 \\
(0.029)\end{array}$ & $\begin{array}{c}0.044 \\
(0.015)\end{array}$ & $\begin{array}{c}0.030 \\
(0.051)\end{array}$ & $\begin{array}{c}0.079 \\
(0.034)\end{array}$ & $\begin{array}{c}0.026 \\
(0.099)\end{array}$ \\
\hline Trends & & $\begin{array}{c}0.011 \\
(0.008)\end{array}$ & & $\begin{array}{l}-0.012 \\
(0.053)\end{array}$ & & $\begin{array}{l}-0.0011 \\
(0.004)\end{array}$ & & $\begin{array}{l}0.0024 \\
(0.008)\end{array}$ & & $\begin{array}{l}0.0098 \\
(0.016)\end{array}$ \\
\hline \multicolumn{11}{|c|}{ Panel B: DMZ Effects } \\
\hline 1995-1997 & $\begin{array}{c}0.002 \\
(0.035)\end{array}$ & $\begin{array}{l}-0.028 \\
(0.071)\end{array}$ & $\begin{array}{c}0.625 \\
(0.299)\end{array}$ & $\begin{array}{c}0.383 \\
(0.359)\end{array}$ & $\begin{array}{c}-0.020 \\
(0.031)\end{array}$ & $\begin{array}{c}0.058 \\
(0.052)\end{array}$ & $\begin{array}{c}0.050 \\
(0.034)\end{array}$ & $\begin{array}{c}0.057 \\
(0.075)\end{array}$ & $\begin{array}{c}-0.047 \\
(0.050)\end{array}$ & $\begin{array}{c}-0.067 \\
(0.116)\end{array}$ \\
\hline $1998-2000$ & $\begin{array}{c}-0.098 \\
(0.037)\end{array}$ & $\begin{array}{l}-0.155 \\
(0.133)\end{array}$ & $\begin{array}{c}0.349 \\
(0.296)\end{array}$ & $\begin{array}{c}-0.129 \\
(0.634)\end{array}$ & $\begin{array}{c}-0.039 \\
(0.030)\end{array}$ & $\begin{array}{c}0.108 \\
(0.079)\end{array}$ & $\begin{array}{c}0.126 \\
(0.036)\end{array}$ & $\begin{array}{c}0.138 \\
(0.127)\end{array}$ & $\begin{array}{c}0.058 \\
(0.063)\end{array}$ & $\begin{array}{c}0.024 \\
(0.191)\end{array}$ \\
\hline Trends & & $\begin{array}{c}0.009 \\
(0.021)\end{array}$ & & $\begin{array}{c}0.077 \\
(0.107)\end{array}$ & & $\begin{array}{l}-0.025 \\
(0.012)\end{array}$ & & $\begin{array}{l}-0.002 \\
(0.020)\end{array}$ & & $\begin{array}{c}0.006 \\
(0.029)\end{array}$ \\
\hline $\mathrm{N}$ & \multicolumn{4}{|c|}{147,833} & \multicolumn{2}{|c|}{74,781} & \multicolumn{2}{|c|}{69,144} & \multicolumn{2}{|c|}{34,451} \\
\hline
\end{tabular}

$\overline{\text { Notes: The table reports pooled growing region/year interactions terms estimated using equation (2) in the text. Estimates for monthly wages omit data for 2000. Standard errors adjusted for department-year }}$ clustering are reported in parentheses. 
TABLE 5a. OUTCOMES FOR CHILDREN - YEARLY INTERACTIONS, POOLED GROWING \& DMZ

\begin{tabular}{|c|c|c|c|c|c|c|c|c|}
\hline \multirow[b]{3}{*}{$\begin{array}{c}\text { Interaction } \\
\text { Terms } \\
\end{array}$} & \multicolumn{4}{|c|}{ Enrollment } & \multicolumn{4}{|c|}{ Labor Market (Teenage Boys) } \\
\hline & \multicolumn{2}{|c|}{ Boys } & \multicolumn{2}{|c|}{ Girls } & \multicolumn{2}{|c|}{ Employment } & \multicolumn{2}{|c|}{ Log Hours (All Jobs) } \\
\hline & $\begin{array}{l}\text { All } \\
(1) \\
\end{array}$ & $\begin{array}{c}\text { w/o } \\
\text { Migrants } \\
(2) \\
\end{array}$ & $\begin{array}{l}\text { All } \\
(3) \\
\end{array}$ & $\begin{array}{c}\text { w/o } \\
\text { Migrants } \\
(4)\end{array}$ & $\begin{array}{l}\text { All } \\
(5) \\
\end{array}$ & $\begin{array}{c}\text { w/o } \\
\text { Migrants } \\
(6) \\
\end{array}$ & $\begin{array}{l}\text { All } \\
(7) \\
\end{array}$ & $\begin{array}{c}\text { w/o } \\
\text { Migrants } \\
(8) \\
\end{array}$ \\
\hline 1994 & $\begin{array}{r}-0.0039 \\
(0.039)\end{array}$ & $\begin{array}{c}-0.042 \\
(0.044)\end{array}$ & $\begin{array}{c}0.054 \\
(0.028)\end{array}$ & $\begin{array}{c}0.044 \\
(0.032)\end{array}$ & $\begin{array}{c}0.021 \\
(0.055)\end{array}$ & $\begin{array}{c}0.025 \\
(0.063)\end{array}$ & $\begin{array}{c}-0.028 \\
(0.071)\end{array}$ & $\begin{array}{l}-0.040 \\
(0.089)\end{array}$ \\
\hline 1995 & $\begin{array}{l}-0.011 \\
(0.037)\end{array}$ & $\begin{array}{c}-0.012 \\
(0.040)\end{array}$ & $\begin{array}{c}0.061 \\
(0.048)\end{array}$ & $\begin{array}{c}0.049 \\
(0.046)\end{array}$ & $\begin{array}{c}-0.037 \\
(0.040)\end{array}$ & $\begin{array}{l}-0.048 \\
(0.039)\end{array}$ & $\begin{array}{c}0.069 \\
(0.078)\end{array}$ & $\begin{array}{c}0.074 \\
(0.083)\end{array}$ \\
\hline 1996 & $\begin{array}{r}-0.0055 \\
(0.032)\end{array}$ & $\begin{array}{l}0.0010 \\
(0.031)\end{array}$ & $\begin{array}{c}0.025 \\
(0.026)\end{array}$ & $\begin{array}{c}0.023 \\
(0.028)\end{array}$ & $\begin{array}{c}0.033 \\
(0.043)\end{array}$ & $\begin{array}{c}0.034 \\
(0.049)\end{array}$ & $\begin{array}{c}0.187 \\
(0.071)\end{array}$ & $\begin{array}{c}0.173 \\
(0.072)\end{array}$ \\
\hline 1997 & $\begin{array}{l}-0.065 \\
(0.033)\end{array}$ & $\begin{array}{c}-0.073 \\
(0.032)\end{array}$ & $\begin{array}{c}0.031 \\
(0.036)\end{array}$ & $\begin{array}{c}0.025 \\
(0.040)\end{array}$ & $\begin{array}{c}0.078 \\
(0.033)\end{array}$ & $\begin{array}{c}0.092 \\
(0.035)\end{array}$ & $\begin{array}{c}0.081 \\
(0.059)\end{array}$ & $\begin{array}{c}0.041 \\
(0.065)\end{array}$ \\
\hline 1998 & $\begin{array}{l}-0.020 \\
(0.034)\end{array}$ & $\begin{array}{c}-0.042 \\
(0.036)\end{array}$ & $\begin{array}{c}0.036 \\
(0.048)\end{array}$ & $\begin{array}{c}0.042 \\
(0.056)\end{array}$ & $\begin{array}{c}0.011 \\
(0.043)\end{array}$ & $\begin{array}{l}0.0009 \\
(0.051)\end{array}$ & $\begin{array}{c}0.228 \\
(0.059)\end{array}$ & $\begin{array}{c}0.243 \\
(0.062)\end{array}$ \\
\hline 1999 & $\begin{array}{l}-0.055 \\
(0.031)\end{array}$ & $\begin{array}{c}-0.052 \\
(0.034)\end{array}$ & $\begin{array}{c}0.017 \\
(0.034)\end{array}$ & $\begin{array}{l}0.0094 \\
(0.040)\end{array}$ & $\begin{array}{c}0.099 \\
(0.038)\end{array}$ & $\begin{array}{c}0.123 \\
(0.042)\end{array}$ & $\begin{array}{c}0.180 \\
(0.054)\end{array}$ & $\begin{array}{c}0.160 \\
(0.061)\end{array}$ \\
\hline 2000 & $\begin{array}{l}-0.054 \\
(0.036)\end{array}$ & $\begin{array}{c}-0.059 \\
(0.040)\end{array}$ & $\begin{array}{c}0.034 \\
(0.034)\end{array}$ & $\begin{array}{c}0.017 \\
(0.036)\end{array}$ & $\begin{array}{c}0.078 \\
(0.050)\end{array}$ & $\begin{array}{c}0.072 \\
(0.053)\end{array}$ & $\begin{array}{c}0.272 \\
(0.047)\end{array}$ & $\begin{array}{c}0.253 \\
(0.053)\end{array}$ \\
\hline $\mathrm{N}$ & 27,382 & 22,695 & 25,771 & 21,259 & 22,365 & 18,319 & 12,528 & 10,104 \\
\hline
\end{tabular}

Notes: The table reports growing region/year interactions. Standard errors adjusted for department-year clustering are reported in parentheses. 
TABLE 5b. OUTCOMES FOR CHILDREN WITH POOLED INTERACTION TERMS

\begin{tabular}{|c|c|c|c|c|c|c|c|c|}
\hline \multirow[b]{3}{*}{$\begin{array}{c}\text { Interaction } \\
\text { Terms } \\
\end{array}$} & \multicolumn{4}{|c|}{ Enrollment } & \multicolumn{4}{|c|}{ Labor Market (Teenage Boys) } \\
\hline & \multicolumn{2}{|c|}{ Boys } & \multicolumn{2}{|c|}{ Girls } & \multicolumn{2}{|c|}{ Employment } & \multicolumn{2}{|c|}{ Log Hours (All Jobs) } \\
\hline & $\begin{array}{c}\text { No Trends } \\
(1) \\
\end{array}$ & $\begin{array}{c}\text { w/Trends } \\
\text { (2) }\end{array}$ & $\begin{array}{c}\text { No Trends } \\
\text { (3) }\end{array}$ & $\begin{array}{c}\text { w/Trends } \\
(4) \\
\end{array}$ & $\begin{array}{c}\text { No Trends } \\
(5) \\
\end{array}$ & $\begin{array}{c}\text { w/Trends } \\
(6) \\
\end{array}$ & $\begin{array}{c}\text { No Trends } \\
(7) \\
\end{array}$ & $\begin{array}{c}\text { w/Trends } \\
\text { (8) } \\
\end{array}$ \\
\hline \multicolumn{9}{|c|}{ Panel A: Growing Effects (non-DMZ) } \\
\hline $1995-1997$ & $\begin{array}{l}-0.0099 \\
(0.024)\end{array}$ & $\begin{array}{c}0.040 \\
(0.046)\end{array}$ & $\begin{array}{c}0.035 \\
(0.024)\end{array}$ & $\begin{array}{c}0.024 \\
(0.051)\end{array}$ & $\begin{array}{c}0.016 \\
(0.030)\end{array}$ & $\begin{array}{c}-0.087 \\
(0.060)\end{array}$ & $\begin{array}{c}0.112 \\
(0.048)\end{array}$ & $\begin{array}{c}0.117 \\
(0.089)\end{array}$ \\
\hline $1998-2000$ & $\begin{array}{c}-0.028 \\
(0.025)\end{array}$ & $\begin{array}{c}0.069 \\
(0.077)\end{array}$ & $\begin{array}{c}0.027 \\
(0.027)\end{array}$ & $\begin{array}{c}0.0059 \\
(0.095)\end{array}$ & $\begin{array}{c}0.073 \\
(0.032)\end{array}$ & $\begin{array}{c}-0.132 \\
(0.096)\end{array}$ & $\begin{array}{c}0.236 \\
(0.040)\end{array}$ & $\begin{array}{c}0.246 \\
(0.143)\end{array}$ \\
\hline Trends & & $\begin{array}{l}-0.016 \\
(0.012)\end{array}$ & & $\begin{array}{c}0.0035 \\
(0.014)\end{array}$ & & $\begin{array}{c}0.034 \\
(0.015)\end{array}$ & & $\begin{array}{l}-0.0016 \\
(0.022)\end{array}$ \\
\hline $\mathrm{N}$ & 27,382 & 27,382 & 25,771 & 25,771 & 22,365 & 22,365 & 12,528 & 12,528 \\
\hline \multicolumn{9}{|c|}{ Panel B: DMZ Effects } \\
\hline 1995-1997 & $\begin{array}{c}-0.103 \\
(0.083)\end{array}$ & $\begin{array}{c}0.174 \\
(0.097)\end{array}$ & $\begin{array}{c}-0.115 \\
(0.069)\end{array}$ & $\begin{array}{c}-0.197 \\
(0.145)\end{array}$ & $\begin{array}{c}-0.032 \\
(0.074)\end{array}$ & $\begin{array}{c}-0.248 \\
(0.196)\end{array}$ & $\begin{array}{c}0.238 \\
(0.095)\end{array}$ & $\begin{array}{c}-0.0041 \\
(0.183)\end{array}$ \\
\hline $1998-2000$ & $\begin{array}{c}-0.079 \\
(0.085)\end{array}$ & $\begin{array}{c}0.436 \\
(0.142)\end{array}$ & $\begin{array}{c}-0.138 \\
(0.072)\end{array}$ & $\begin{array}{c}-0.293 \\
(0.223)\end{array}$ & $\begin{array}{c}-0.213 \\
(0.088)\end{array}$ & $\begin{array}{c}-0.612 \\
(0.377)\end{array}$ & $\begin{array}{c}0.232 \\
(0.093)\end{array}$ & $\begin{array}{l}-0.216 \\
(0.332)\end{array}$ \\
\hline Trends & & $\begin{array}{l}-0.087 \\
(0.021)\end{array}$ & & $\begin{array}{c}0.025 \\
(0.030)\end{array}$ & & $\begin{array}{c}0.066 \\
(0.053)\end{array}$ & & $\begin{array}{c}0.071 \\
(0.048)\end{array}$ \\
\hline $\mathrm{N}$ & 27,3 & 382 & 25, & 771 & 22, & 365 & 12,5 & 528 \\
\hline
\end{tabular}

Notes: The table reports pooled growing region/year interactions terms estimated using equation (2) in the text. Estimates for monthly wages omit data for 2000. Standard errors adjusted for department-year clustering are reported in parentheses. 
TABLE 6. ADULT AND TEENAGE LABOR MARKET OUTCOMES - RURAL AND URBAN EFFECTS

Male and Female Workers

\begin{tabular}{cc}
\multicolumn{2}{c}{ Men Only } \\
\hline $\begin{array}{c}\text { Log Hours } \\
\text { (All Jobs) }\end{array}$ & $\begin{array}{c}\text { Log Monthly Wage and } \\
\text { Salary Earnings }\end{array}$ \\
\cline { 1 - 1 } 14 growing no med prod. &
\end{tabular}

\begin{tabular}{c} 
Teenage Boys \\
\hline Log Hours \\
(All Jobs) \\
\hline 14 growing no med prod
\end{tabular}

\begin{tabular}{|c|c|c|c|c|c|c|c|c|c|c|}
\hline \multirow[b]{2}{*}{$\begin{array}{c}\text { Interaction } \\
\text { Terms }\end{array}$} & & & & & \\
\hline & $\begin{array}{c}14 \text { growing } \\
(1)\end{array}$ & $\begin{array}{c}\text { no med. prod. } \\
\text { (2) }\end{array}$ & $\begin{array}{l}14 \text { growing } \\
\text { (3) }\end{array}$ & $\begin{array}{c}\text { no med. prod. } \\
(4)\end{array}$ & $\begin{array}{l}14 \text { growing } \\
\text { (5) } \\
\end{array}$ & $\begin{array}{c}\text { no med. prod. } \\
(6)\end{array}$ & $\begin{array}{l}14 \text { growing } \\
(7)\end{array}$ & $\begin{array}{c}\text { no med. prod. } \\
(8) \\
\end{array}$ & $\begin{array}{l}14 \text { growing } \\
(9)\end{array}$ & $\begin{array}{c}\text { no med. prod. } \\
\text { (10) }\end{array}$ \\
\hline \multicolumn{11}{|c|}{ Panel A: Rural Effects } \\
\hline 1995-1997 & $\begin{array}{c}0.006 \\
(0.032)\end{array}$ & $\begin{array}{c}0.017 \\
(0.032)\end{array}$ & $\begin{array}{c}0.286 \\
(0.162)\end{array}$ & $\begin{array}{c}0.328 \\
(0.175)\end{array}$ & $\begin{array}{c}0.037 \\
(0.025)\end{array}$ & $\begin{array}{c}0.061 \\
(0.029)\end{array}$ & $\begin{array}{l}-0.019 \\
(0.058)\end{array}$ & $\begin{array}{c}-0.024 \\
(0.071)\end{array}$ & $\begin{array}{l}0.119 * \\
(0.082)\end{array}$ & $\begin{array}{l}0.122 * \\
(0.078)\end{array}$ \\
\hline $1998-2000$ & $\begin{array}{l}-0.031 \\
(0.047)\end{array}$ & $\begin{array}{l}-0.029 \\
(0.044)\end{array}$ & $\begin{array}{c}0.295 \\
(0.253)\end{array}$ & $\begin{array}{c}0.316 \\
(0.304)\end{array}$ & $\begin{array}{c}0.079 \\
(0.039)\end{array}$ & $\begin{array}{c}0.127 \\
(0.043)\end{array}$ & $\begin{array}{l}0.045^{*} \\
(0.095)\end{array}$ & $\begin{array}{c}0.022 \\
(0.110)\end{array}$ & $\begin{array}{l}0.216 * \\
(0.128)\end{array}$ & $\begin{array}{l}0.210^{*} \\
(0.129)\end{array}$ \\
\hline \multicolumn{11}{|c|}{ Panel B: Urban Effects } \\
\hline 1995-1997 & $\begin{array}{c}0.013 \\
(0.027)\end{array}$ & $\begin{array}{l}-0.015 \\
(0.024)\end{array}$ & $\begin{array}{c}0.155 \\
(0.128)\end{array}$ & $\begin{array}{c}0.186 \\
(0.146)\end{array}$ & $\begin{array}{c}0.025 \\
(0.020)\end{array}$ & $\begin{array}{c}0.042 \\
(0.023)\end{array}$ & $\begin{array}{l}-0.038 \\
(0.057)\end{array}$ & $\begin{array}{l}-0.060 \\
(0.059)\end{array}$ & $\begin{array}{l}-0.004 \\
(0.072)\end{array}$ & $\begin{array}{l}-0.006 \\
(0.181)\end{array}$ \\
\hline $1998-2000$ & $\begin{array}{l}-0.019 \\
(0.050)\end{array}$ & $\begin{array}{l}-0.053 \\
(0.042)\end{array}$ & $\begin{array}{c}0.174 \\
(0.207)\end{array}$ & $\begin{array}{c}0.190 \\
(0.247)\end{array}$ & $\begin{array}{c}0.040 \\
(0.033)\end{array}$ & $\begin{array}{c}0.079 \\
(0.037)\end{array}$ & $\begin{array}{l}-0.087 \\
(0.088)\end{array}$ & $\begin{array}{l}-0.137 \\
(0.094)\end{array}$ & $\begin{array}{l}-0.047 \\
(0.127)\end{array}$ & $\begin{array}{l}-0.010 \\
(0.134)\end{array}$ \\
\hline Trend & $\begin{array}{c}0.01 \\
(0.007)\end{array}$ & $\begin{array}{c}0.014 \\
(0.007)\end{array}$ & $\begin{array}{l}-0.004 \\
(0.033)\end{array}$ & $\begin{array}{l}-0.021 \\
(0.039)\end{array}$ & $\begin{array}{l}-0.005 \\
(0.006)\end{array}$ & $\begin{array}{l}-0.014 \\
(0.006)\end{array}$ & $\begin{array}{c}0.011 \\
(0.014)\end{array}$ & $\begin{array}{c}0.016 \\
(0.016)\end{array}$ & $\begin{array}{c}0.001 \\
(0.019)\end{array}$ & $\begin{array}{l}-0.006 \\
(0.020)\end{array}$ \\
\hline $\mathrm{N}$ & 482,053 & 477,346 & 116,896 & 113,831 & 192,840 & 189,003 & 101,779 & 100,338 & 22,141 & 21,084 \\
\hline
\end{tabular}

$\overline{\text { Notes: The table reports results from a stacked urban and rural sample. Estimates for monthly wages omit data for 2000. Standard errors adjusted for department-year clustering are reported in parentheses. }{ }^{*} *{ }^{\prime} \text { denotes a }}$ significant rural-urban difference. Columns labelled "14 growing" use the same growing region as in Tables 4 and 5 . Columns labelled "no medium producers," drop the 5 medium producing departments from the analysis. 
TABLE 7. MORTALITY ESTIMATES

\begin{tabular}{|c|c|c|c|c|c|c|c|c|}
\hline & \multicolumn{4}{|c|}{14 Growing Departments } & \multicolumn{4}{|c|}{ No Medium Producers } \\
\hline & \multicolumn{2}{|c|}{ No trends } & \multicolumn{2}{|c|}{ With trends } & \multicolumn{2}{|c|}{ No trends } & \multicolumn{2}{|c|}{ With trends } \\
\hline & $\begin{array}{c}\text { Growing } \\
\text { (1) }\end{array}$ & $\begin{array}{c}\text { DMZ } \\
(2) \\
\end{array}$ & $\begin{array}{c}\text { Growing } \\
(3)\end{array}$ & $\begin{array}{c}\text { DMZ } \\
(4) \\
\end{array}$ & $\begin{array}{c}\text { Growing } \\
(5)\end{array}$ & $\begin{array}{c}\text { DMZ } \\
(6) \\
\end{array}$ & $\begin{array}{c}\text { Growing } \\
(7)\end{array}$ & $\begin{array}{c}\mathrm{DMZ} \\
(8) \\
\end{array}$ \\
\hline \multicolumn{9}{|c|}{ A. Unweighted } \\
\hline 1993 & $\begin{array}{c}0.026 \\
(0.118)\end{array}$ & $\begin{array}{c}-0.059 \\
(0.149)\end{array}$ & & & $\begin{array}{c}0.012 \\
(0.170)\end{array}$ & $\begin{array}{c}-0.059 \\
(0.149)\end{array}$ & & \\
\hline 1994 & $\begin{array}{c}0.123 \\
(0.120)\end{array}$ & $\begin{array}{c}-0.078 \\
(0.123)\end{array}$ & $\begin{array}{c}0.133 \\
(0.161)\end{array}$ & $\begin{array}{l}-0.145 \\
(0.192)\end{array}$ & $\begin{array}{c}0.209 \\
(0.162)\end{array}$ & $\begin{array}{c}-0.077 \\
(0.122)\end{array}$ & $\begin{array}{c}0.255 \\
(0.222)\end{array}$ & $\begin{array}{l}-0.145 \\
(0.192)\end{array}$ \\
\hline 1995 & $\begin{array}{c}0.102 \\
(0.096)\end{array}$ & $\begin{array}{c}0.198 \\
(0.165)\end{array}$ & $\begin{array}{c}0.118 \\
(0.188)\end{array}$ & $\begin{array}{c}0.098 \\
(0.286)\end{array}$ & $\begin{array}{c}0.236 \\
(0.131)\end{array}$ & $\begin{array}{c}0.198 \\
(0.164)\end{array}$ & $\begin{array}{c}0.302 \\
(0.261)\end{array}$ & $\begin{array}{c}0.097 \\
(0.285)\end{array}$ \\
\hline 1996 & $\begin{array}{c}0.154 \\
(0.114)\end{array}$ & $\begin{array}{c}0.266 \\
(0.132)\end{array}$ & $\begin{array}{c}0.176 \\
(0.241)\end{array}$ & $\begin{array}{c}0.134 \\
(0.342)\end{array}$ & $\begin{array}{c}0.289 \\
(0.142)\end{array}$ & $\begin{array}{c}0.266 \\
(0.132)\end{array}$ & $\begin{array}{c}0.374 \\
(0.331)\end{array}$ & $\begin{array}{c}0.132 \\
(0.340)\end{array}$ \\
\hline 1997 & $\begin{array}{c}0.230 \\
(0.132)\end{array}$ & $\begin{array}{c}0.402 \\
(0.178)\end{array}$ & $\begin{array}{c}0.259 \\
(0.296)\end{array}$ & $\begin{array}{c}0.237 \\
(0.434)\end{array}$ & $\begin{array}{c}0.346 \\
(0.154)\end{array}$ & $\begin{array}{c}0.403 \\
(0.178)\end{array}$ & $\begin{array}{c}0.451 \\
(0.402)\end{array}$ & $\begin{array}{c}0.236 \\
(0.431)\end{array}$ \\
\hline 1998 & $\begin{array}{c}0.200 \\
(0.152)\end{array}$ & $\begin{array}{c}0.514 \\
(0.170)\end{array}$ & $\begin{array}{c}0.235 \\
(0.346)\end{array}$ & $\begin{array}{c}0.315 \\
(0.505)\end{array}$ & $\begin{array}{c}0.506 \\
(0.197)\end{array}$ & $\begin{array}{c}0.514 \\
(0.170)\end{array}$ & $\begin{array}{c}0.631 \\
(0.482)\end{array}$ & $\begin{array}{c}0.314 \\
(0.501)\end{array}$ \\
\hline 1999 & $\begin{array}{c}0.197 \\
(0.102)\end{array}$ & $\begin{array}{c}0.340 \\
(0.140)\end{array}$ & $\begin{array}{c}0.238 \\
(0.383)\end{array}$ & $\begin{array}{c}0.109 \\
(0.572)\end{array}$ & $\begin{array}{c}0.259 \\
(0.142)\end{array}$ & $\begin{array}{c}0.340 \\
(0.140)\end{array}$ & $\begin{array}{c}0.403 \\
(0.534)\end{array}$ & $\begin{array}{c}0.107 \\
(0.568)\end{array}$ \\
\hline 2000 & $\begin{array}{c}0.289 \\
(0.100)\end{array}$ & $\begin{array}{c}0.142 \\
(0.148)\end{array}$ & $\begin{array}{c}0.337 \\
(0.432)\end{array}$ & $\begin{array}{c}-0.122 \\
(0.651)\end{array}$ & $\begin{array}{c}0.358 \\
(0.120)\end{array}$ & $\begin{array}{c}0.142 \\
(0.147)\end{array}$ & $\begin{array}{c}0.522 \\
(0.601)\end{array}$ & $\begin{array}{l}-0.124 \\
(0.646)\end{array}$ \\
\hline Dept. trend & & & $\begin{array}{l}-0.006 \\
(0.052)\end{array}$ & $\begin{array}{c}0.033 \\
(0.079)\end{array}$ & & & $\begin{array}{l}-0.020 \\
(0.072)\end{array}$ & $\begin{array}{c}0.033 \\
(0.078)\end{array}$ \\
\hline & & & & 3eight & & & & \\
\hline 1993 & $\begin{array}{c}-0.080 \\
(0.109)\end{array}$ & $\begin{array}{c}-0.100 \\
(0.144)\end{array}$ & & & $\begin{array}{c}-0.202 \\
(0.113)\end{array}$ & $\begin{array}{c}-0.101 \\
(0.145)\end{array}$ & & \\
\hline 1994 & $\begin{array}{c}0.045 \\
(0.095)\end{array}$ & $\begin{array}{c}-0.137 \\
(0.099)\end{array}$ & $\begin{array}{c}0.097 \\
(0.140)\end{array}$ & $\begin{array}{c}-0.105 \\
(0.167)\end{array}$ & $\begin{array}{c}0.062 \\
(0.093)\end{array}$ & $\begin{array}{c}-0.137 \\
(0.100)\end{array}$ & $\begin{array}{c}0.283 \\
(0.137)\end{array}$ & $\begin{array}{c}-0.105 \\
(0.168)\end{array}$ \\
\hline 1995 & $\begin{array}{c}0.141 \\
(0.081)\end{array}$ & $\begin{array}{c}0.126 \\
(0.135)\end{array}$ & $\begin{array}{c}0.205 \\
(0.171)\end{array}$ & $\begin{array}{c}0.159 \\
(0.240)\end{array}$ & $\begin{array}{c}0.183 \\
(0.103)\end{array}$ & $\begin{array}{c}0.125 \\
(0.136)\end{array}$ & $\begin{array}{c}0.473 \\
(0.187)\end{array}$ & $\begin{array}{c}0.159 \\
(0.241)\end{array}$ \\
\hline 1996 & $\begin{array}{c}0.163 \\
(0.134)\end{array}$ & $\begin{array}{c}0.178 \\
(0.139)\end{array}$ & $\begin{array}{c}0.241 \\
(0.239)\end{array}$ & $\begin{array}{c}0.214 \\
(0.296)\end{array}$ & $\begin{array}{c}0.180 \\
(0.158)\end{array}$ & $\begin{array}{c}0.178 \\
(0.140)\end{array}$ & $\begin{array}{c}0.538 \\
(0.262)\end{array}$ & $\begin{array}{c}0.214 \\
(0.297)\end{array}$ \\
\hline 1997 & $\begin{array}{c}0.179 \\
(0.115)\end{array}$ & $\begin{array}{c}0.260 \\
(0.140)\end{array}$ & $\begin{array}{c}0.269 \\
(0.270)\end{array}$ & $\begin{array}{c}0.298 \\
(0.353)\end{array}$ & $\begin{array}{c}0.220 \\
(0.130)\end{array}$ & $\begin{array}{c}0.259 \\
(0.141)\end{array}$ & $\begin{array}{c}0.647 \\
(0.293)\end{array}$ & $\begin{array}{c}0.298 \\
(0.354)\end{array}$ \\
\hline 1998 & $\begin{array}{c}0.120 \\
(0.100)\end{array}$ & $\begin{array}{c}0.434 \\
(0.146)\end{array}$ & $\begin{array}{c}0.222 \\
(0.308)\end{array}$ & $\begin{array}{c}0.474 \\
(0.412)\end{array}$ & $\begin{array}{c}0.169 \\
(0.110)\end{array}$ & $\begin{array}{c}0.434 \\
(0.147)\end{array}$ & $\begin{array}{c}0.665 \\
(0.334)\end{array}$ & $\begin{array}{c}0.475 \\
(0.414)\end{array}$ \\
\hline 1999 & $\begin{array}{c}0.313 \\
(0.092)\end{array}$ & $\begin{array}{c}0.296 \\
(0.112)\end{array}$ & $\begin{array}{c}0.428 \\
(0.350)\end{array}$ & $\begin{array}{c}0.339 \\
(0.461)\end{array}$ & $\begin{array}{c}0.369 \\
(0.110)\end{array}$ & $\begin{array}{c}0.296 \\
(0.113)\end{array}$ & $\begin{array}{c}0.934 \\
(0.384)\end{array}$ & $\begin{array}{c}0.339 \\
(0.463)\end{array}$ \\
\hline 2000 & $\begin{array}{c}0.388 \\
(0.097)\end{array}$ & $\begin{array}{c}0.119 \\
(0.122)\end{array}$ & $\begin{array}{c}0.516 \\
(0.397)\end{array}$ & $\begin{array}{c}0.163 \\
(0.524)\end{array}$ & $\begin{array}{c}0.401 \\
(0.106)\end{array}$ & $\begin{array}{c}0.118 \\
(0.123)\end{array}$ & $\begin{array}{c}1.034 \\
(0.433)\end{array}$ & $\begin{array}{c}0.164 \\
(0.526)\end{array}$ \\
\hline Dept. trend & & & $\begin{array}{l}-0.013 \\
(0.046)\end{array}$ & $\begin{array}{l}-0.002 \\
(0.062)\end{array}$ & & & $\begin{array}{l}-0.069 \\
(0.052)\end{array}$ & $\begin{array}{c}-0.002 \\
(0.062)\end{array}$ \\
\hline
\end{tabular}

Notes: The table reports results of regressions with log violent death rates on left hand side, controlling for department, year and age effects and estimated using statistics aggregated by department, year, and 10-year age groups, for men aged 15-64. Standard errors adjusted for department-year clustering are in parentheses. 
TABLE 8. MORTALITY ESTIMATES BY URBAN/RURAL RESIDENCE

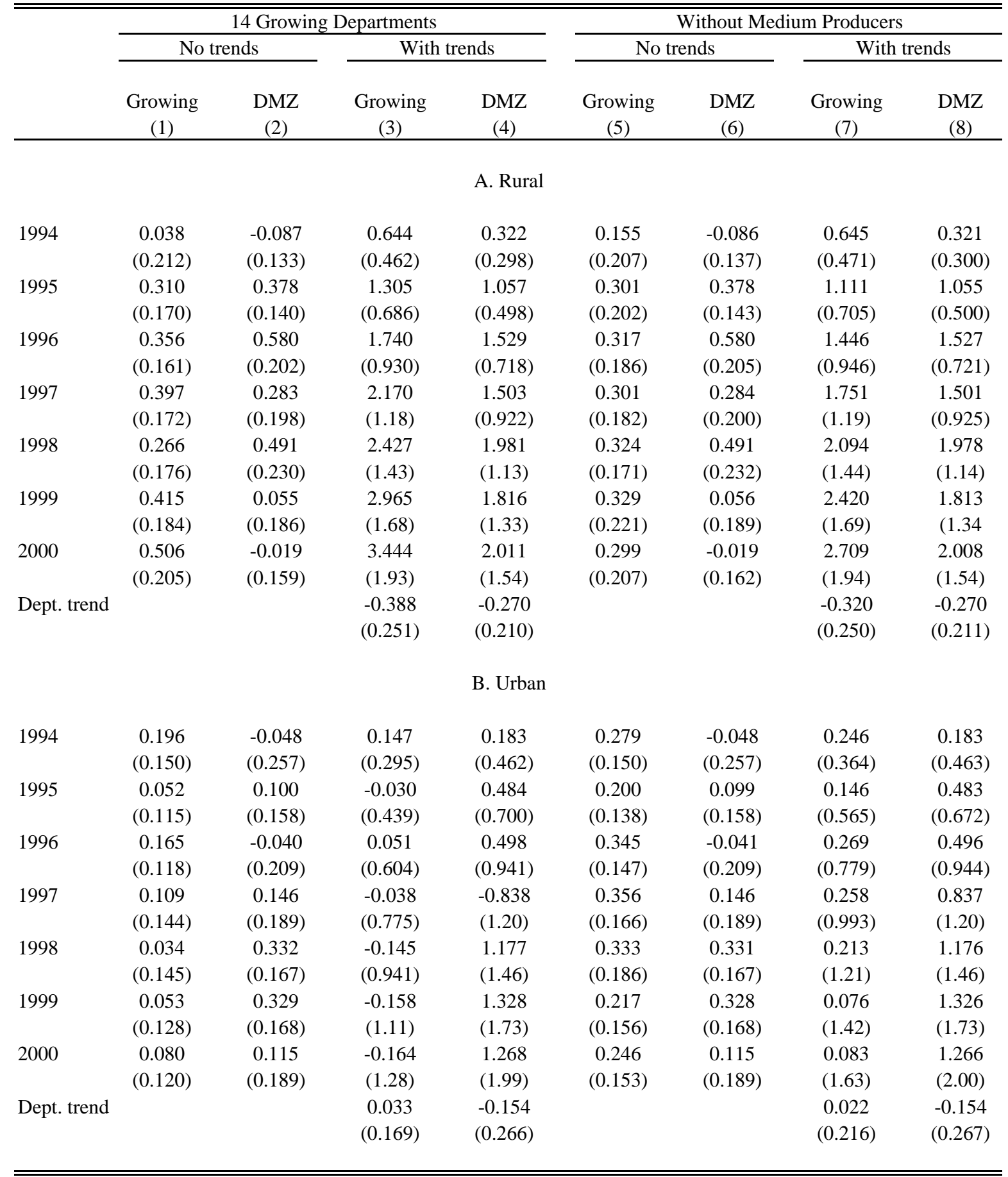

Notes: The table reports unweighted estimates from regressions with log violent death rates on left hand side, controlling for department, year and age effects. The model is estimated using statistics aggregated by department, year, and 10-year age groups, for men aged 15-64. Standard errors adjusted for department-year clustering are in parentheses. 
Fig. 1. Production of Coca Leaf in Colombia, Peru and Bolivia 1990-2000

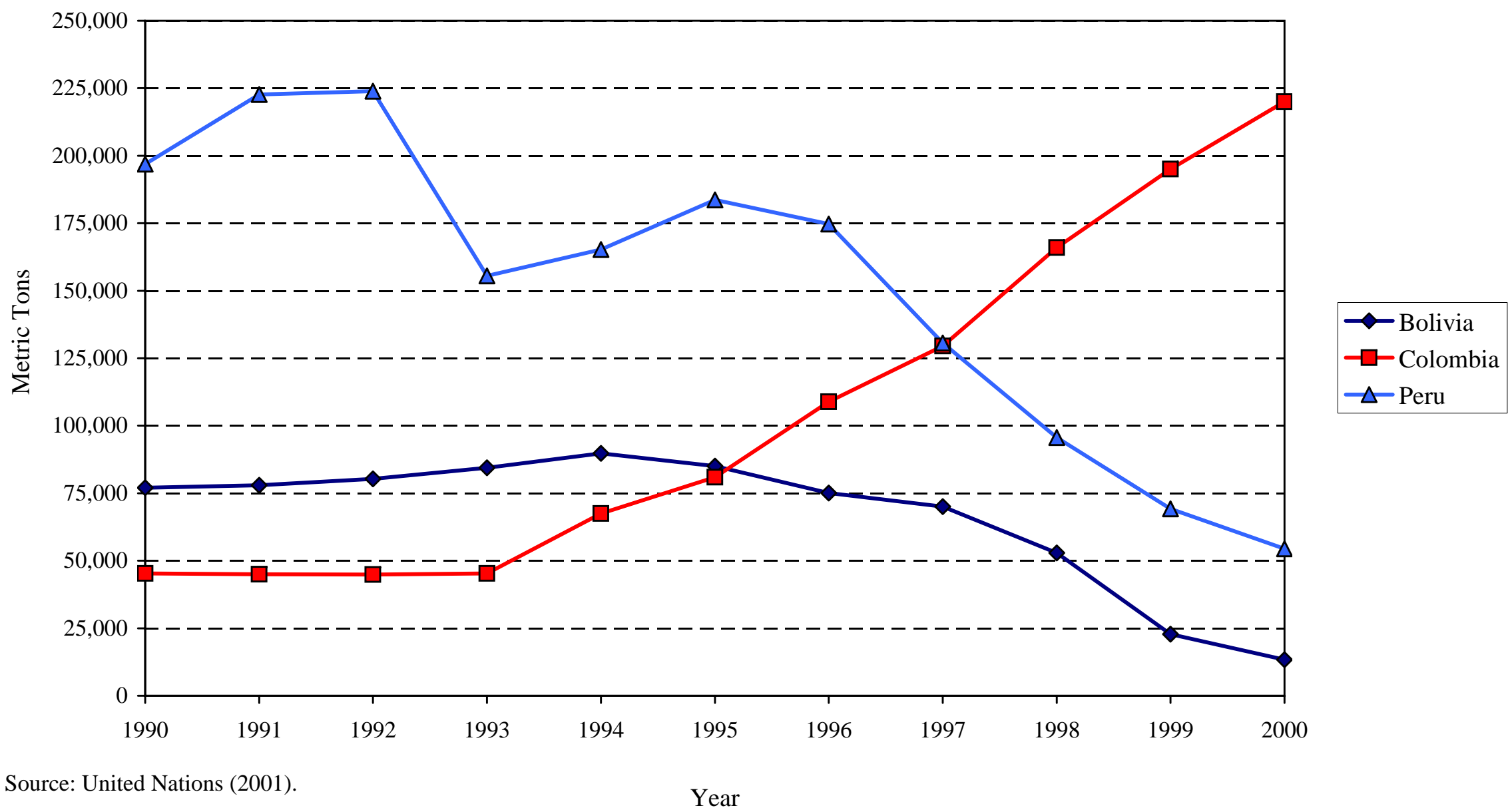


Fig. 2a. Per-Capita GDP Growth Rate for Selected South American Countries 1990-2000

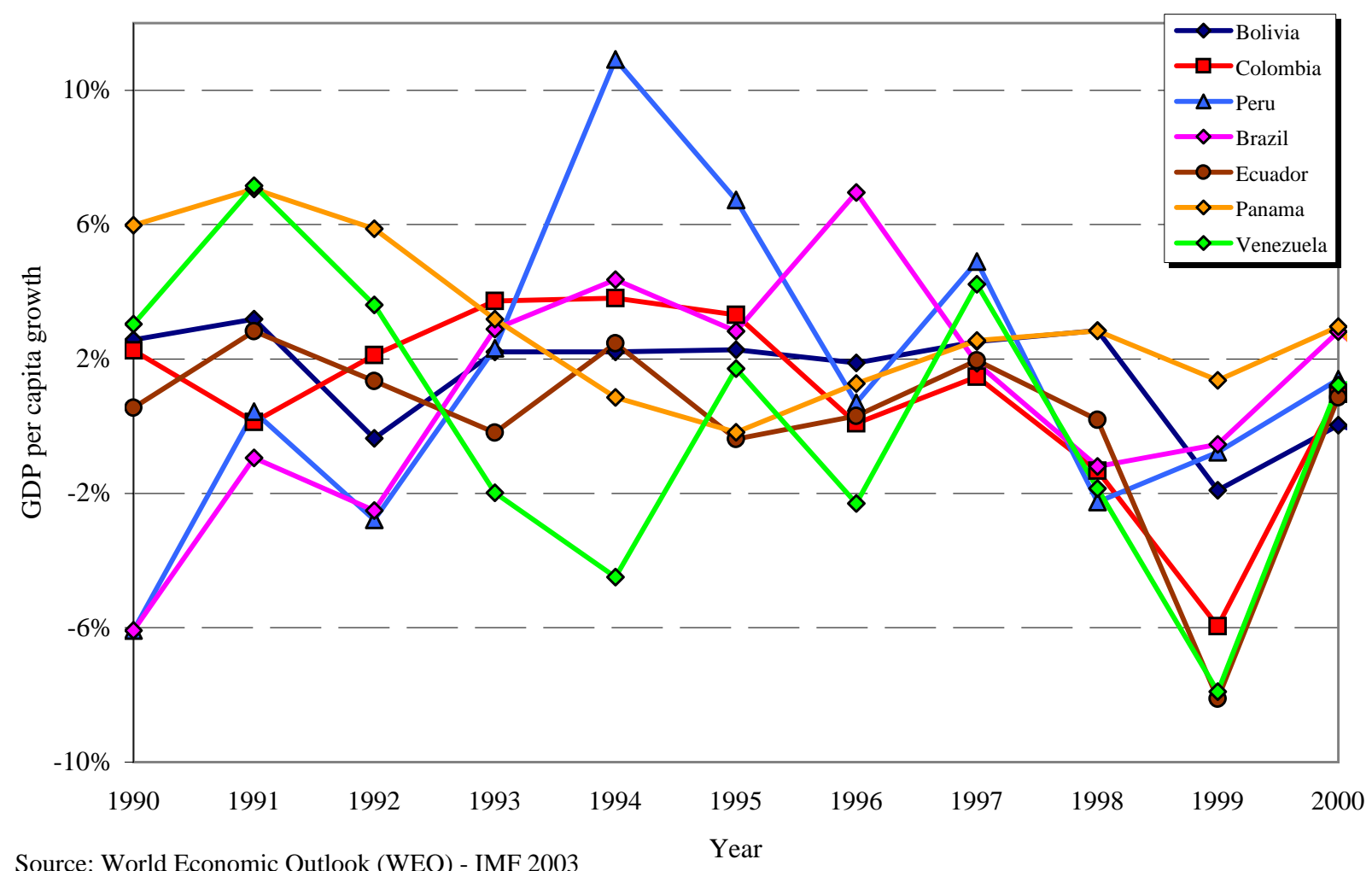

Fig. 2b. Homicide Rate in Selected South American Countries 1990-2000

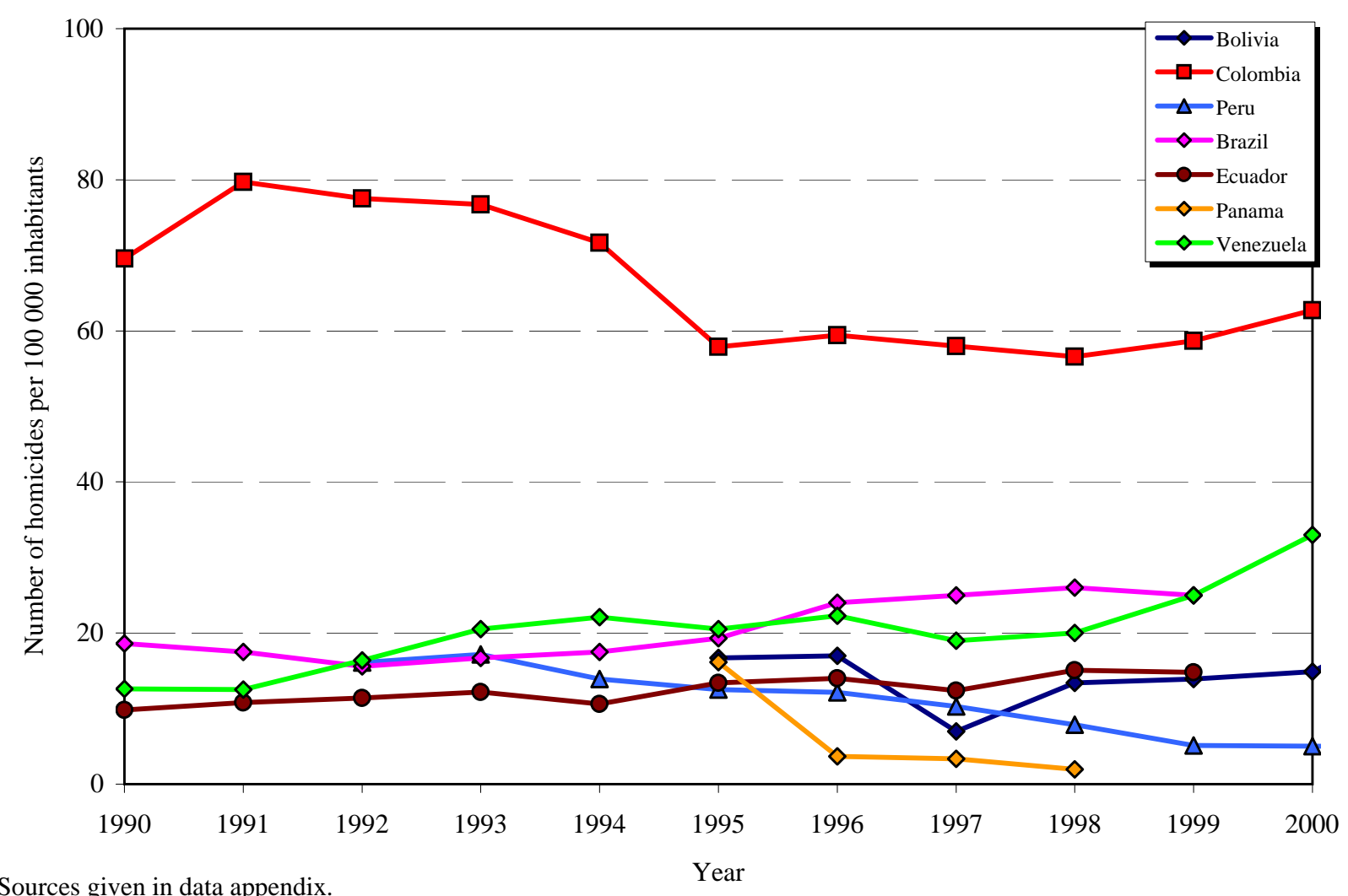

Sources given in data appendix. 
Fig. 3. Coca Cultivation: 1994-99 growth as a function of 1994 levels

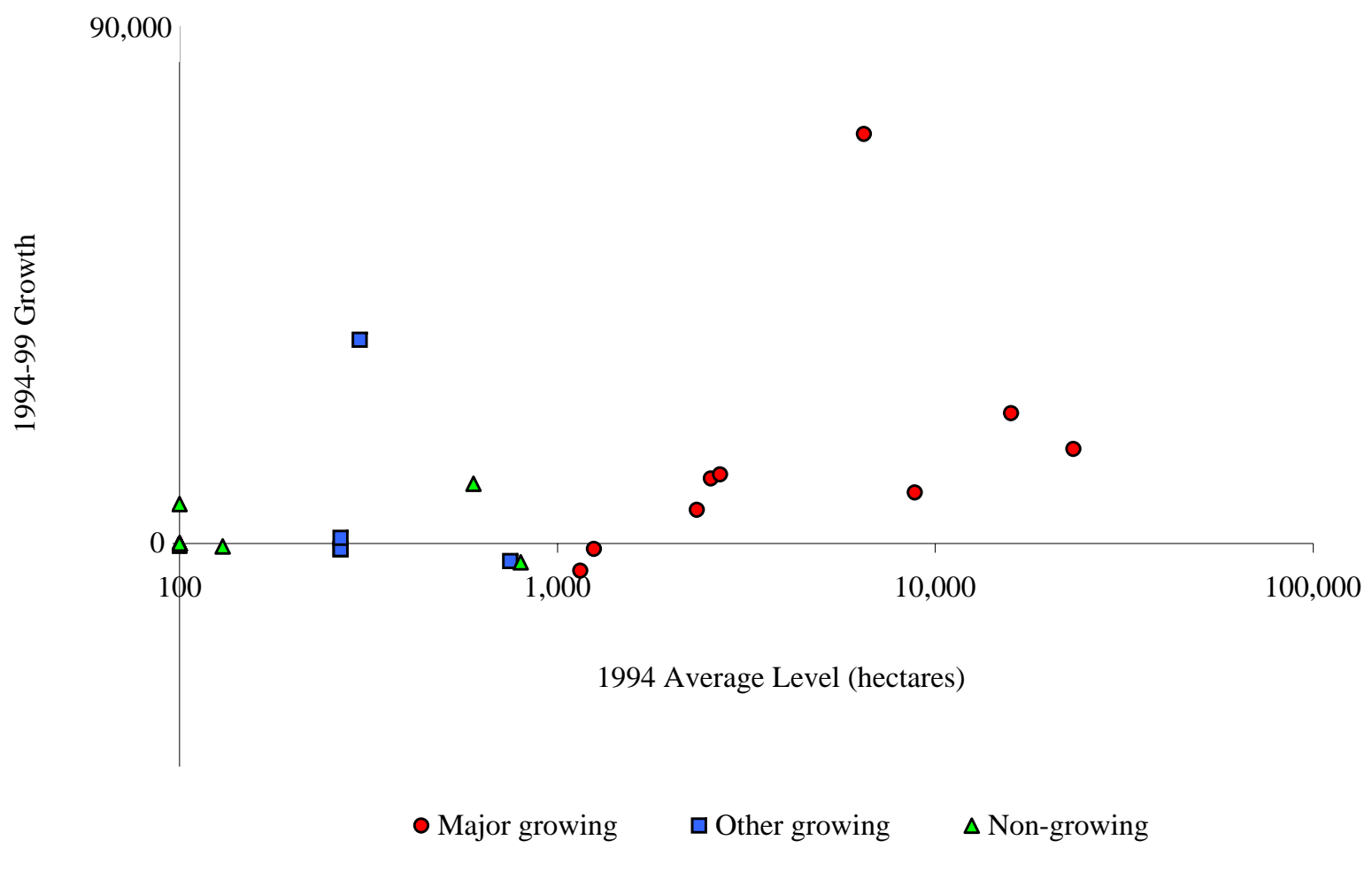

Notes: Scales are logarithmic. The 100 hectare base group includes 100 or less. 
Figure 4. Death Rates for Men Aged 15 - 59.

(a) Violence

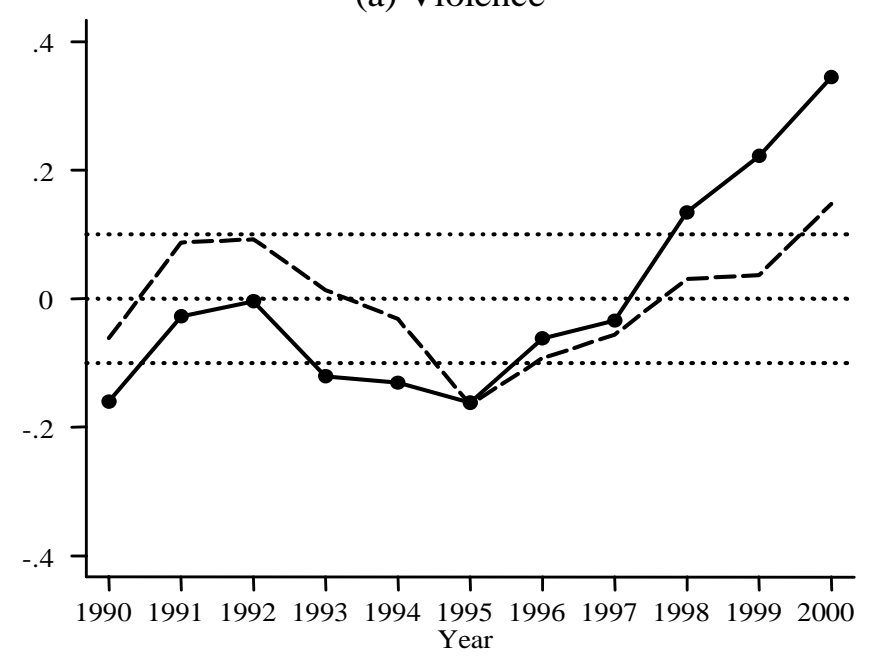

Department Type

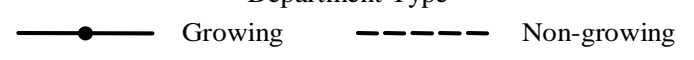

(b) Disease

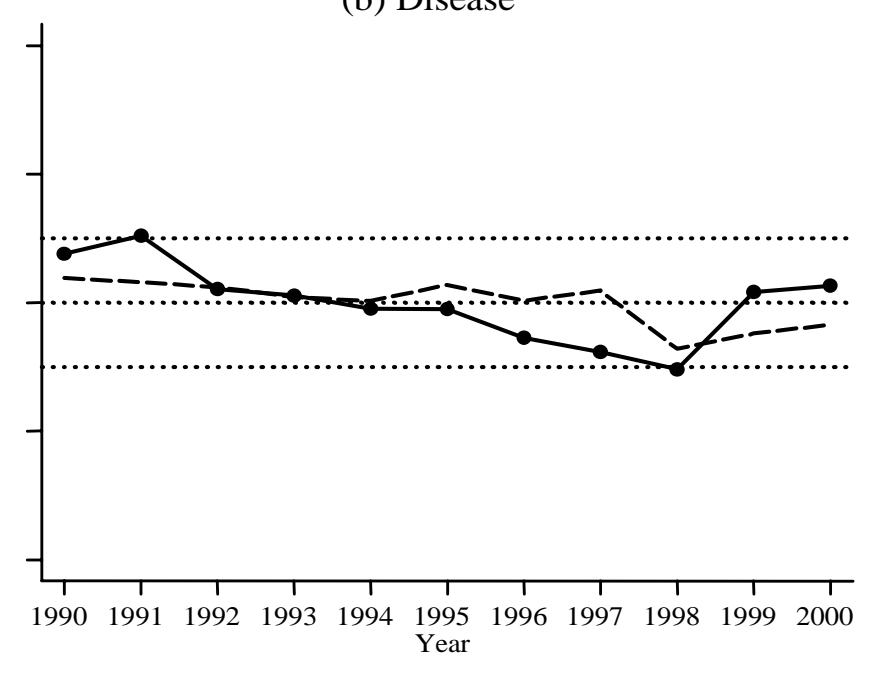

Department Type

Notes:

1. Log rates, relative to average by department type.

2. Non-growing omits Antioquia, Valle, and Bogota DC. 
Fig. 5. Death Rates for Men Aged 15 - 59

(a) Violence

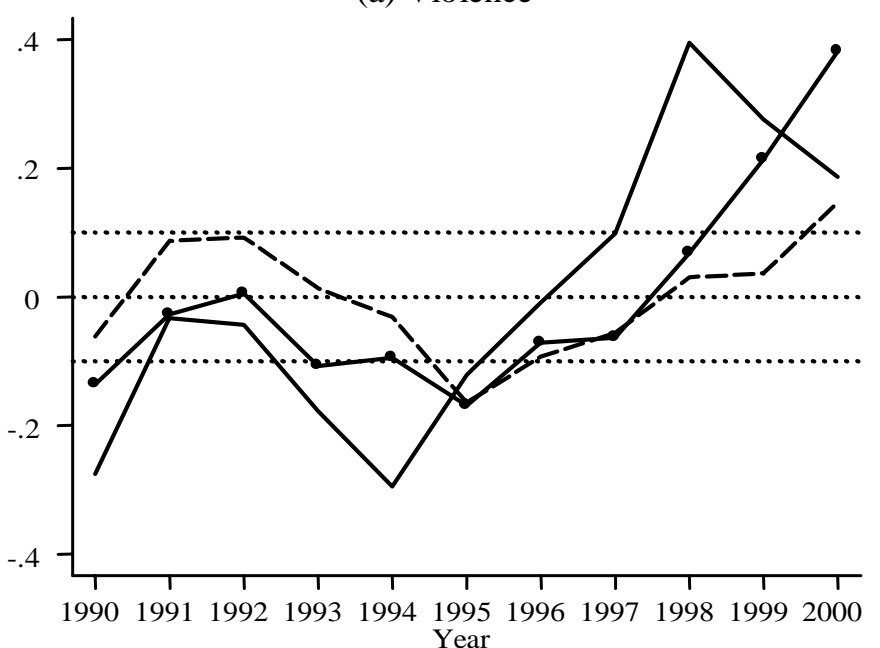

Department Type

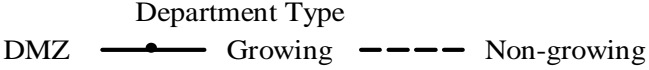

(b) Disease

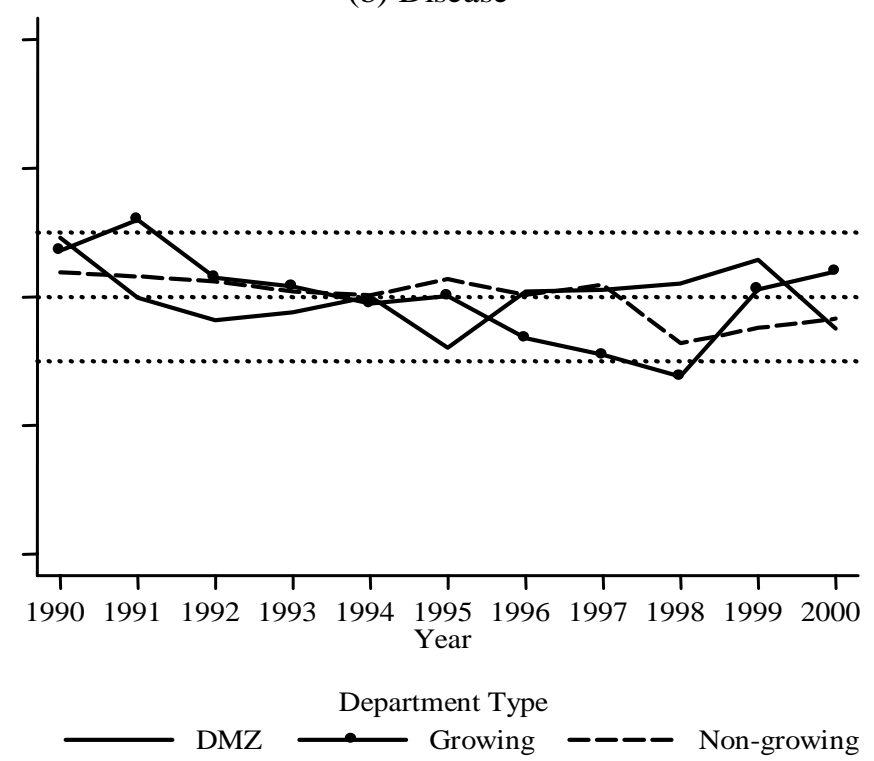

Notes:

Notes:
1. Log rates, relative to average by department type

2. Non-growing omits Antioquia, Valle, and Bogota DC. 
Fig. 6. Death Rates - Logit(Violence/Total) -- for Men Aged 15 - 59
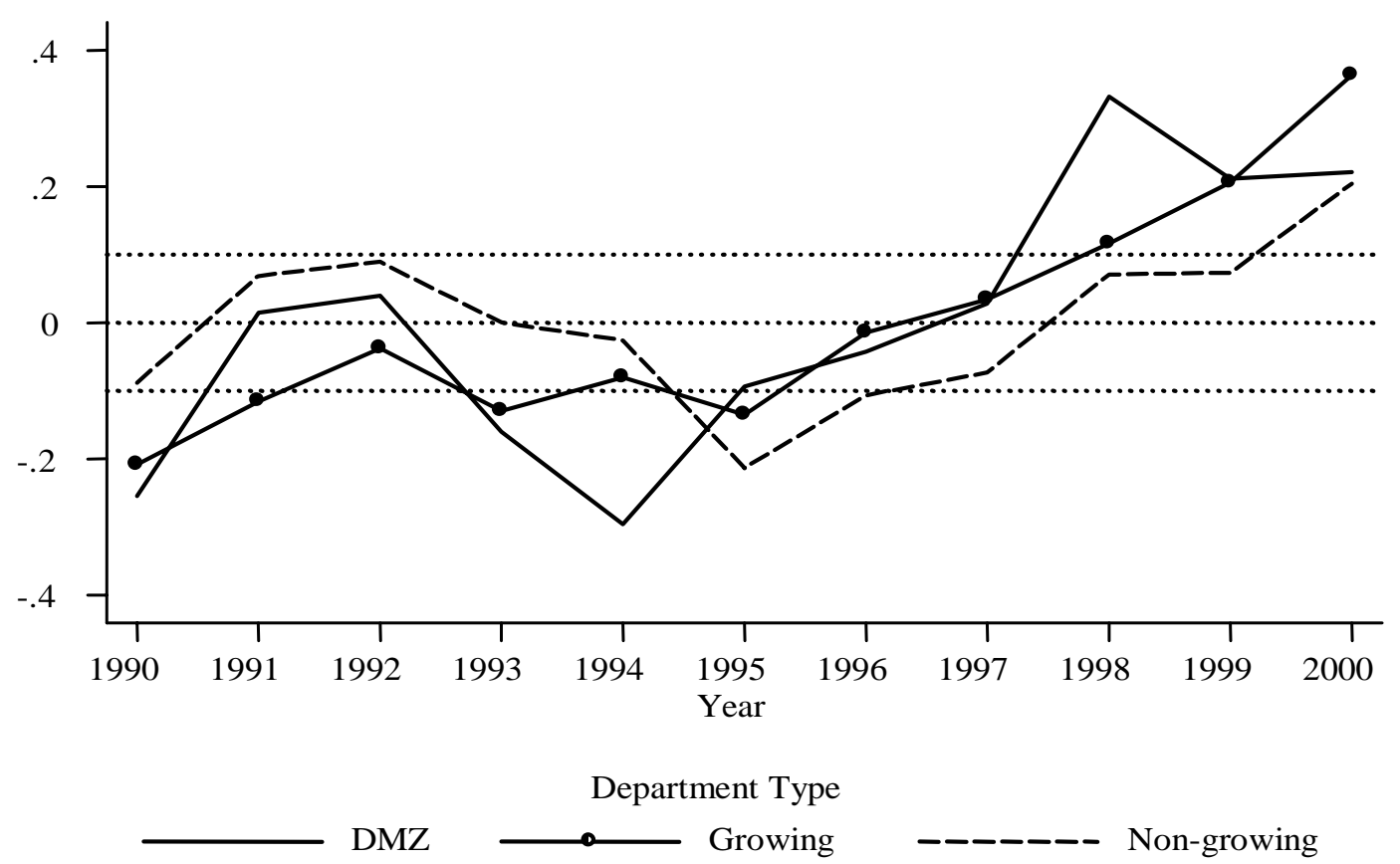

Notes:

2. Non-growing omits Antioquia, Valle, and Bogota DC. 